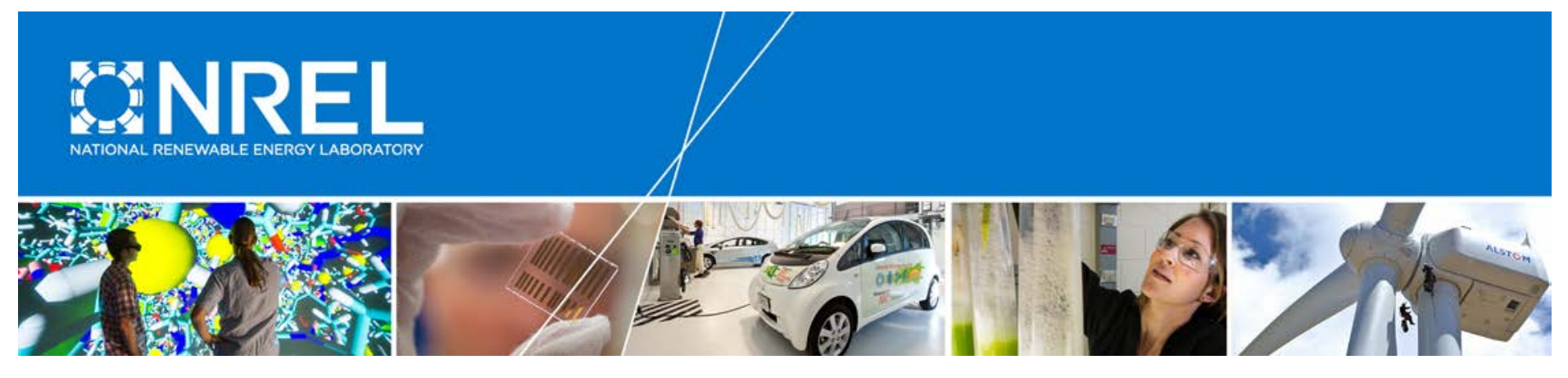

\title{
A Non-Modeling Exploration of Residential Solar Photovoltaic (PV) Adoption and Non-Adoption 09/18/13 - 07/15/16
}

Mithra Moezzi, Aaron Ingle, and Loren Lutzenhiser Portland State University

Benjamin Sigrin National Renewable Energy Laboratory

NREL Technical Monitor: Benjamin Sigrin

NREL is a national laboratory of the U.S. Department of Energy Office of Energy Efficiency \& Renewable Energy Operated by the Alliance for Sustainable Energy, LLC

This report is available at no cost from the National Renewable Energy Laboratory (NREL) at www.nrel.gov/publications.

Technical Report

NREL/SR-6A20-67727

September 2017 


\section{A Non-Modeling Exploration of Residential Solar Photovoltaic (PV) Adoption and Non-Adoption}

Mithra Moezzi, Aaron Ingle, and

Loren Lutzenhiser

Portland State University

Benjamin Sigrin

National Renewable Energy Laboratory

NREL Technical Monitor: Benjamin Sigrin

Prepared under Subcontract No. XGN-3-23453-01

NREL is a national laboratory of the U.S. Department of Energy Office of Energy Efficiency \& Renewable Energy Operated by the Alliance for Sustainable Energy, LLC

This report is available at no cost from the National Renewable Energy Laboratory (NREL) at www.nrel.gov/publications.

National Renewable Energy Laboratory 15013 Denver West Parkway Golden, CO 80401

303-275-3000 • www.nrel.gov
Technical Report

NREL/SR-6A20-67727

September 2017

Contract No. DE-AC36-08G028308 


\section{NOTICE}

This report was prepared as an account of work sponsored by an agency of the United States government. Neither the United States government nor any agency thereof, nor any of their employees, makes any warranty, express or implied, or assumes any legal liability or responsibility for the accuracy, completeness, or usefulness of any information, apparatus, product, or process disclosed, or represents that its use would not infringe privately owned rights. Reference herein to any specific commercial product, process, or service by trade name, trademark, manufacturer, or otherwise does not necessarily constitute or imply its endorsement, recommendation, or favoring by the United States government or any agency thereof. The views and opinions of authors expressed herein do not necessarily state or reflect those of the United States government or any agency thereof.

This report is available at no cost from the National Renewable Energy Laboratory (NREL) at www.nrel.gov/publications.

Available electronically at SciTech Connect http:/www.osti.gov/scitech

Available for a processing fee to U.S. Department of Energy and its contractors, in paper, from:

U.S. Department of Energy

Office of Scientific and Technical Information

P.O. Box 62

Oak Ridge, TN 37831-0062

OSTI http://www.osti.gov

Phone: 865.576.8401

Fax: 865.576.5728

Email: reports@osti.gov

Available for sale to the public, in paper, from:

U.S. Department of Commerce

National Technical Information Service

5301 Shawnee Road

Alexandria, VA 22312

NTIS http://www.ntis.gov

Phone: 800.553 .6847 or 703.605 .6000

Fax: 703.605.6900

Email: orders@ntis.gov 


\section{Acknowledgements}

This work was funded by the Solar Energy Technologies Office of the U.S. Department of Energy's Office of Energy Efficiency and Renewable Energy for the Solar Energy Evolution and Diffusion Studies program under contract number DE-AC36-08GO28308. The report authors would like to gratefully acknowledge the entire project research team-Thomas Dietz, Changgui Dong, Easan Drury, Adam Henry, Georgia Pfeiffer, Seth Spielman, Paul Stern, Annika Todd, James Tong, Ryan Wiser, and Kim Wolske. We also thank Ria Langheim, James McCall, Eric O'Shaughnessy, and Jarrett Zuboy for the invaluable comments. Finally, we thank the installers and lead generators who collaborated with us both as individuals and as companies as well as all of the survey respondents. Opinions represented in this report are the authors' own and do not reflect the view of the U.S. Department of Energy or the U.S. Government. 


\section{List of Acronyms}

$\mathrm{AC}$

EIA

GPS

PV

TPO air conditioning

U.S. Energy Information Administration

general population survey

photovoltaic(s)

third-party ownership 


\section{Executive Summary}

Although U.S. deployment of residential rooftop solar photovoltaic (PV) systems has accelerated in recent years, PV is currently installed on less than $1 \%$ of single-family homes. Most research on household PV adoption has focused on scaling initial markets and modeling predicted growth, rather than on considering more broadly why, socio-culturally, adoption does or does not occur. Studies that have investigated PV adoption have typically collected data from adopters only or otherwise treated non-adopters as a largely undifferentiated group. Yet, the vast majority of Americans are non-adopters of PV, and not just "pre-adopters." They have widely varying attitudes toward PV, varying levels of consideration, and varying circumstances (Figure ES-1). Understanding their ways of evaluating PV adoption is thus important to understanding future adoption and how it might evolve. In addition, little research has investigated the experiences of households after installing PV. This report helps fill some of these gaps in the existing literature. The results inform a more detailed understanding of residential PV adoption, consideration, and non-adoption, as well as attitudes and experiences with PV overall.

The report draws on a diverse set of survey data to examine residential PV adoption and nonadoption, the varieties of adopters and non-adopters, and the roles of policies and marketing in shaping these segments. The survey data were collected from nearly 3,600 single-family, owneroccupied households across four different states: Arizona, California, New Jersey, and New York. We divided the survey respondents into four groups: (1) the general population survey (GPS) "Not Thought" group, which had not considered installing PV, (2) the GPS "Thought Not Bought" group, which had considered installing PV "seriously" but had not installed it, (3) "Considerers," which had previous contact with a solar installer for their home but chose not to proceed with adoption, and (4) the PV Adopter group. Figure ES-1 depicts the group characteristics. Comparing survey results across these groups enables an improved understanding about what influences adoption and non-adoption of residential PV.
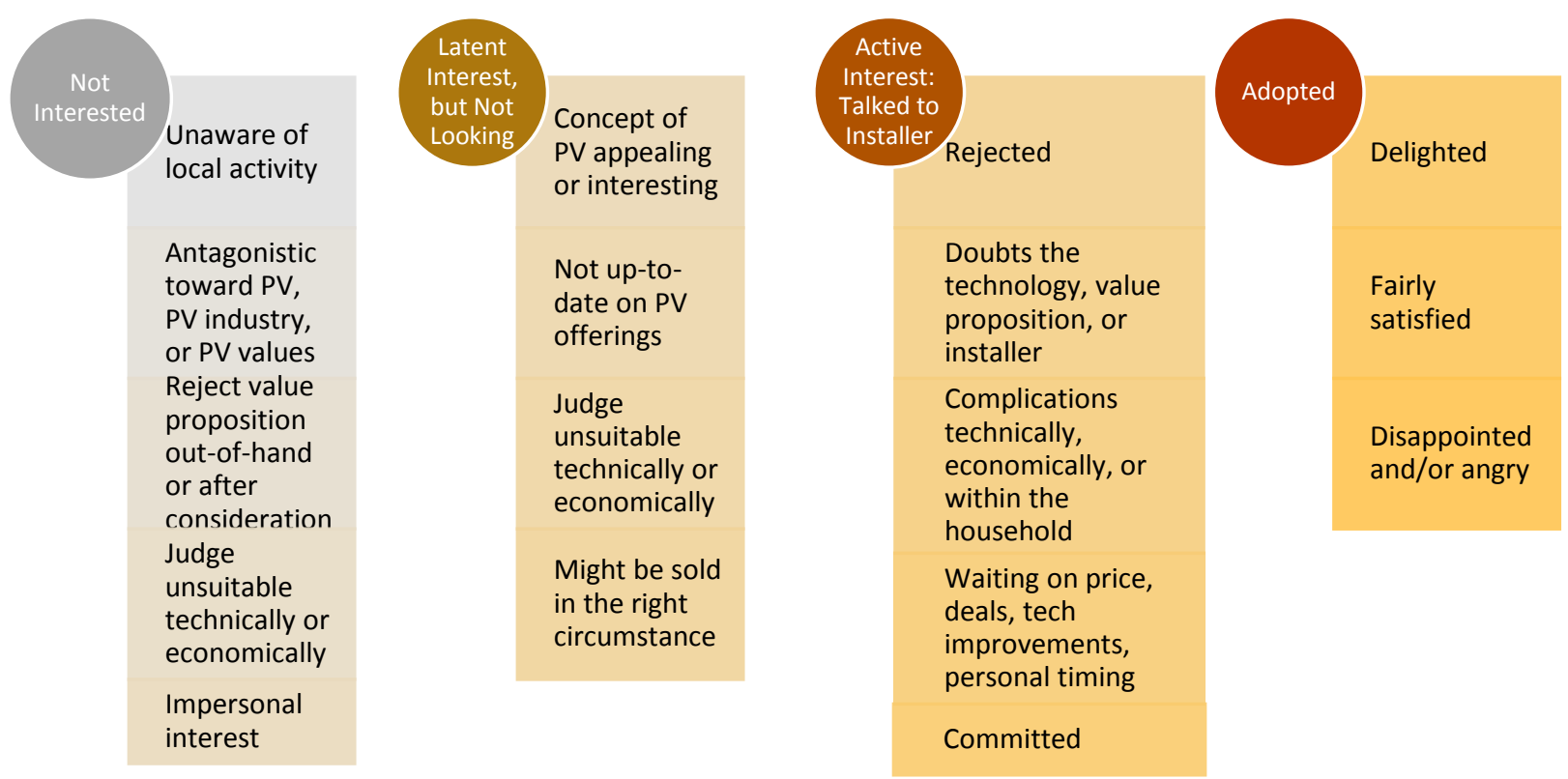

Figure ES-1. Summarized categories of household statuses with respect to rooftop PV 
We interpret these data through a social scientific lens in the context of current theories and literature about PV adoption. Our deliberately open and exploratory approach provides a relatively natural view of household PV experiences and contrasts with prediction-centered statistical or simulation-modeling approaches.

\section{PV Non-Adopters: Lack of Awareness, Financial Skepticism, and Other Factors}

Most of the general population surveyed who reported not having considered PV said they were largely unaware of local PV activities and were not interested in learning more about PV. A third of the general population surveyed (representing all households other than PV adopters) said that they had not encountered recent PV advertising, had not received calls about PV, knew no more than one person with PV, had not talked to anyone who had PV, and did not know of friends or neighbors who had it. To the extent that awareness is a prerequisite for adoption, a large group of households has not yet been made palpably aware of the technology. While this is likely partly because the technology is not salient to their situation, it may also represent a certain narrowness of information channels about PV.

On the other hand, about half of the general population who said they had thought about installing PV more or less seriously (the GPS-Thought Not Bought group) were interested in talking to an installer or hearing of local homeowners' experiences with PV. What is striking is that few $(9 \%)$ had actually talked to an installer. This indicates a potentially large untapped interest in PV assessment; many households are aware of PV and may be quite receptive to a PV installer approaching them but had not yet been approached.

To clarify why non-adopters had not considered or not adopted PV, we analyzed the prevalence of conditions and concerns that might discourage adoption (Table ES-1). The most common factor was the lack of a compelling financial rationale, followed by a more specific concern about possibly not staying in the home long enough for the PV investment to pay off. The latter speaks both to the long time scale of investment as well as personal uncertainties. The importance of financial considerations to non-adoption is underscored by a comparison of the general population group who had not thought about PV versus Adopter group. Only $17 \%$ of the former said PV would provide a great return on investment, compared with $64 \%$ of Adopters. That is, many non-interested households reject the value proposition out of hand. 
Table ES-1. Percentage of General Population Survey (GPS) Groups Potentially Dissuaded from PV Installation

\begin{tabular}{|c|c|c|}
\hline \multirow{2}{*}{ Percentage Dissuaded From Adoption by Concern } & \multicolumn{2}{|c|}{ General Population Survey } \\
\hline & $\begin{array}{l}\text { Not Thought } \\
\text { (About Solar) }\end{array}$ & $\begin{array}{c}\text { Thought (About Solar) } \\
\text { Not Bought }\end{array}$ \\
\hline \multicolumn{3}{|l|}{ Financial } \\
\hline Not compelling financially & $66 \%$ & $59 \%$ \\
\hline Cannot afford & $35 \%$ & $27 \%$ \\
\hline Not at all interested in savings & $27 \%$ & $4 \%$ \\
\hline Low bills (average electricity bill under $\$ 100 / \mathrm{m}$ ) & $36 \%$ & $24 \%$ \\
\hline \multicolumn{3}{|l|}{ Long-Term Involvement } \\
\hline May not be in home long enough & $57 \%$ & $45 \%$ \\
\hline Age over 75 & $20 \%$ & $13 \%$ \\
\hline \multicolumn{3}{|l|}{ Technical/Pragmatic } \\
\hline Perceive technical conditions to be unsuitable & $24 \%$ & $17 \%$ \\
\hline Think it is better to wait & $41 \%$ & $43 \%$ \\
\hline \multicolumn{3}{|l|}{ Information } \\
\hline Low trust in information sources & $49 \%$ & $28 \%$ \\
\hline \multicolumn{3}{|l|}{ Risks and Burdens } \\
\hline Concerned with maintenance & $19 \%$ & $18 \%$ \\
\hline Perceived as hassle to install & $32 \%$ & $30 \%$ \\
\hline Concerned with damage to roof & $16 \%$ & $15 \%$ \\
\hline Perceive solar as risky & $34 \%$ & $31 \%$ \\
\hline \multicolumn{3}{|l|}{ Social, Political, or Personal } \\
\hline Not aligned w/environmental/climate causes & $27 \%$ & $11 \%$ \\
\hline Embarrassed to have panels visible on roof & $9 \%$ & $5 \%$ \\
\hline Family/friends would not support & $15 \%$ & $8 \%$ \\
\hline
\end{tabular}

As Table ES-1 shows, a substantial portion of non-adopters thought it was better to wait for PV technology improvements or price reductions. A lack of trust in PV-related information sources was commonly cited as a reason for not considering adoption. In fact, most of the general population surveyed expressed very low levels of trust in information from PV installers, solar industry organizations, and utilities. Environmental organizations and government were trusted only moderately overall. The most trusted information sources were friends, family, and neighbors; yet peers experienced with PV are rare in certain geographies and social groups.

A variety of perceived technology-related risks and burdens also discouraged adoption of PV, including uncertainty about performance, installation difficulties, and concerns about maintenance and roof damage. Social, political, and personal influences also play roles. Most strikingly, while the environmental aspects of PV are often assumed to encourage its adoption, many ( $27 \%$ of those who said they had not thought about PV) described themselves as opposed to or unaligned with environmental or climate change causes. In contrast, of those who had thought about PV, less than half of that proportion (11\%) said the same. Environmental beliefs- 
which can encourage PV adoption among some groups - might discourage it among others. Similarly, peers can discourage as well as encourage adoption. Even if all technical or economic conditions are conducive from an outside perspective, some individuals are not interested in adopting PV, whether because they see no need, view the adoption process as being a hassle, have high levels of distrust, or are against PV or the symbolic interpretations they give it.

\section{Deciding to Adopt: Saving Money while Helping the Environment}

Saving money was the most prominent reason stated for PV adoption, followed by wanting to reduce one's environmental impacts. Table ES-2 shows the percentages of Adopters who marked "extremely important" for a variety of motives.

Table ES-2. Strong Adopter Motivations for Considering PV

\begin{tabular}{lc}
\hline Motivations & $\begin{array}{c}\text { Percent of Adopters Responding } \\
\text { "Extremely Important" }\end{array}$ \\
\hline Lowering your total electricity costs & $78 \%$ \\
Protection from rising electricity prices in the future & $62 \%$ \\
Being able to use renewable energy & $50 \%$ \\
Reducing your environmental impact & $43 \%$ \\
Getting a good return on investment & $33 \%$ \\
Being able to use a promising new technology & $30 \%$ \\
Setting a positive example for others in your community & $26 \%$ \\
Adding to your home's market value & $23 \%$ \\
\hline
\end{tabular}

Behind these overall statistics, adopters exhibit a variety of combinations of motivations. One third of PV Adopters ranked both saving money and reducing environmental impact as extremely important, while the highest proportion (45\%) of the total prioritized saving money. Only $9 \%$ prioritized the environment over saving money, and less than $1 \%$ said that only the environment, not saving money was important. Reducing environmental impact was rarely the dominant stated motivation, whereas saving money often was. Concerns about money, can take various forms - from initial investment and on-going costs to ensuring a healthy rate of return, protecting against rising electricity prices, reducing energy-related financial stresses at home, and more. Simple economic metrics cannot capture these complexities well.

Across our surveys, non-adopters who had at least considered installing PV designated themselves pro-environmental as frequently as PV Adopters, whereas those who had not considered PV were far less likely to do so. The environmental associations of PV may play a more important role in initial PV interest or disinterest than in later stages of consideration. In addition, social values, such as being able to use a promising new technology or setting a positive example for others were considered very important more often than even increasing home value. So, it is clear that PV adoption is not just an objective proposition based on technical and economic considerations but can also be emotional and symbolic.

\section{PV Adoption-Decision Processes: Deliberative or Opportunistic?}

PV may often be in a "sold, not bought" category of goods. This status contrasts with a common storyline that assumes most PV adoption starts with marked interest and a relatively tight 
accompanying rationale, such as saving money while protecting the environment. Some households in our study seem deliberative about deciding to adopt PV, carefully weighing costs and benefits. But our data suggest that a substantial portion of adoption decisions may be more impressionistic or opportunistic, in particular arising when an installer connects to a homeowner who was not actively seeking PV. These relatively casual adopters may be very satisfied with their decision. Thus modeling PV adoption in a strictly deliberative framework may overlook these more opportunistic adoption decisions. The general population survey results suggest high levels of latent interest in PV (GPS-Thought not Bought group), though, given our results on more opportunistic purchases, even some of those who said they had not thought about PV (GPS-Not Thought group) might as easily be sold on it.

\section{Considering but Not Adopting PV}

We also looked at cases where households seriously consider PV but had not (at the time of the survey) installed it. Only $11 \%$ of such households said they had rejected PV outright or were not currently considering installing it, whereas $60 \%$ said they were still considering or undecided. Most of the rest (23\%) said they had decided to install but had not yet acted. As shown in Table ES-3, directly financial concerns - doubts about affordability, the sufficiency of bill savings ("enough bang for the buck"), the wisdom of the financial decision, and taking on debt or signing a lease-were all stopping points for more than half of those who had seriously considered PV. Concerns about the aesthetics of PV or selling a home with PV were the least common, with about half saying they had little to no concern in these regards. Even so, aesthetics and impact on the home's sales value remained bothersome enough to nearly a third of those who considered PV to stop consideration.

Table ES-3. Percentages of Considerers Expressing Various Concerns about PV Adoption

\begin{tabular}{lcc}
\hline How concerned were you about...? & $\begin{array}{c}\text { "Not at All or } \\
\text { Slightly" }\end{array}$ & $\begin{array}{c}\text { "Stopped } \\
\text { Consideration of PV" }\end{array}$ \\
\hline Affordability & $19 \%$ & $58 \%$ \\
Taking on debt or signing a lease & $25 \%$ & $55 \%$ \\
Whether solar was a good financial decision & $18 \%$ & $53 \%$ \\
Whether panels offered enough bang for buck & $17 \%$ & $50 \%$ \\
Equipment quality and reliability over time & $16 \%$ & $44 \%$ \\
Risk of damaging your roof & $30 \%$ & $40 \%$ \\
Having to perform regular maintenance & $25 \%$ & $37 \%$ \\
\hline Might be harder to sell home with solar panels & $54 \%$ & $30 \%$ \\
\hline Might detract from home's "curb appeal" & $49 \%$ & $29 \%$ \\
\hline
\end{tabular}




\section{Table of Contents}

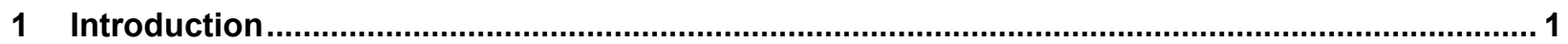

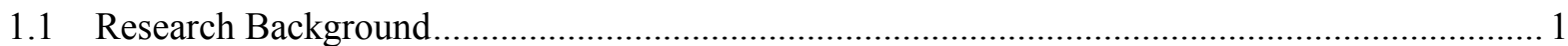

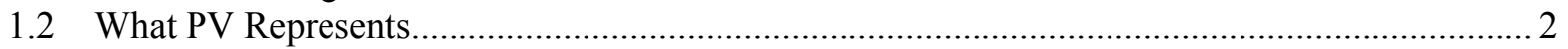

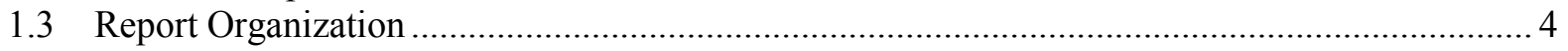

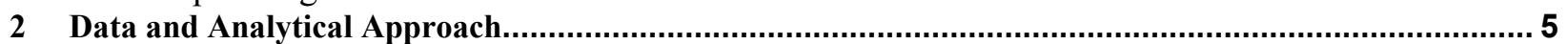

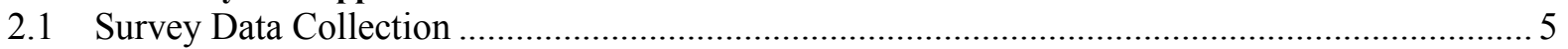

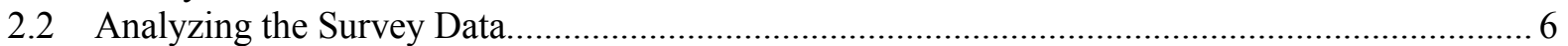

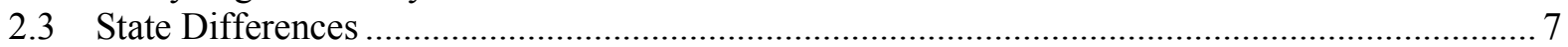

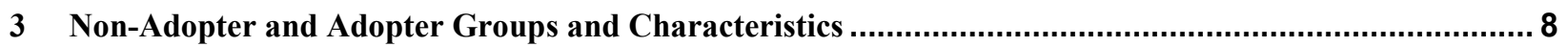

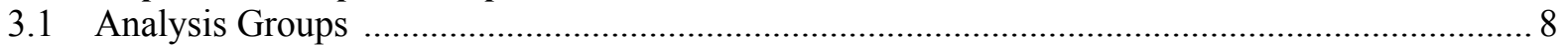

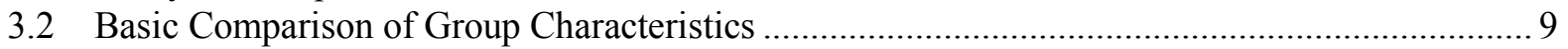

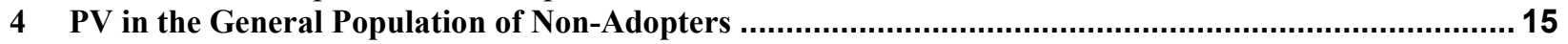

4.1 From Antagonism to Interest: Levels of Interest in the General Population.............................. 15

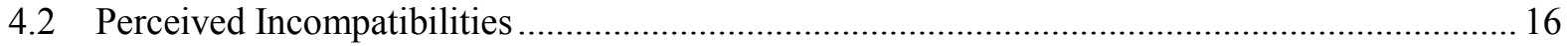

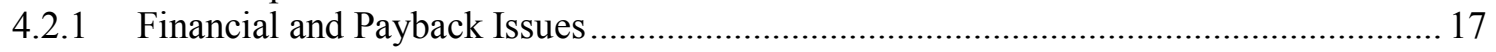

4.2.2 Waiting for Technology Improvements or Price Reductions ....................................... 18

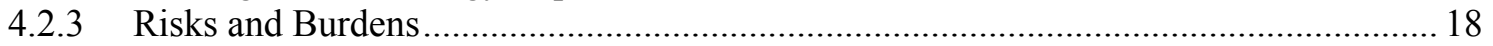

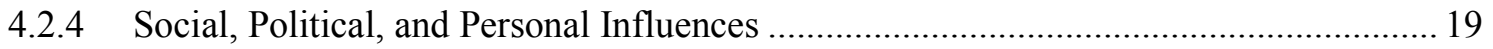

4.3 Perceptions of PV Economics in the General Population ........................................................ 20

4.4 Perceptions of Non-Economic, Non-Environmental PV Attributes in the General Population.. 21

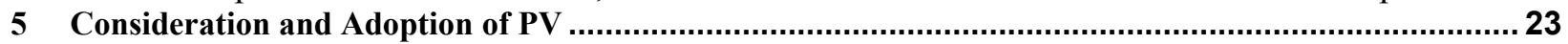

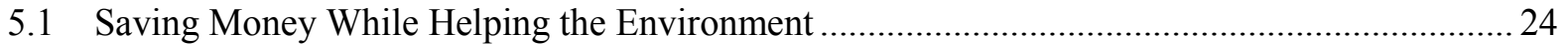

5.2 Depth of Environmental Interest, Concern, and Commitment ............................................... 26

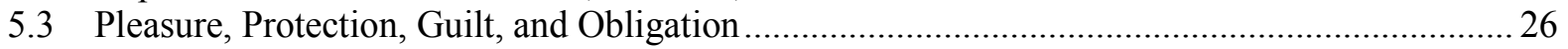

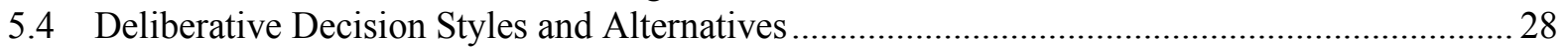

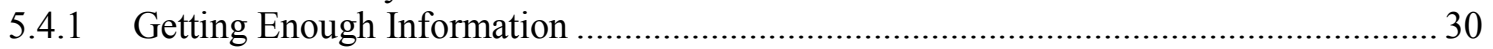

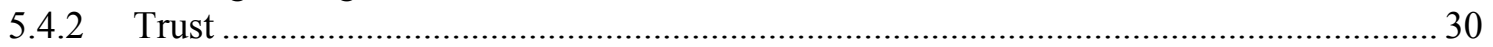

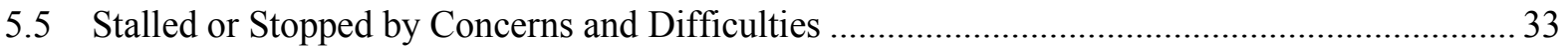

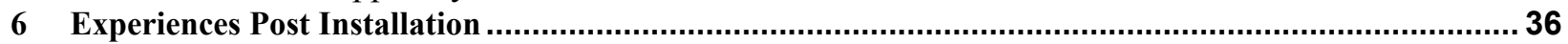

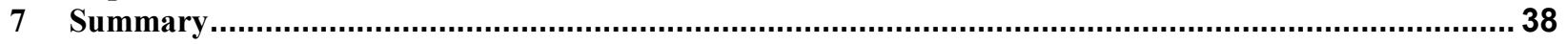

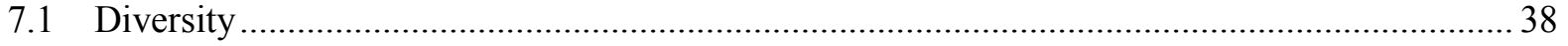

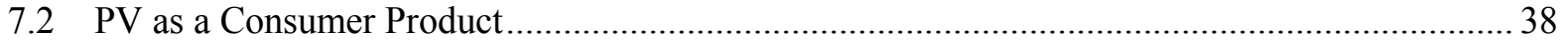

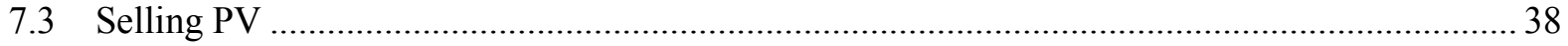

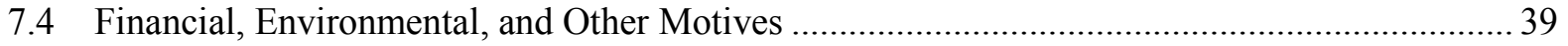

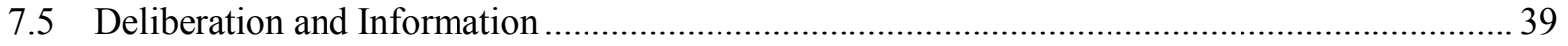

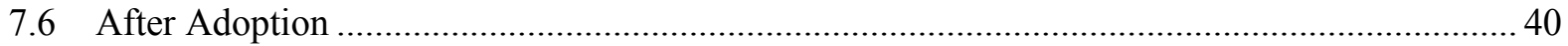

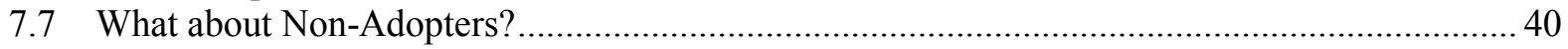

8 Questions about PV's Future, Questions for Future Research......................................................... 41

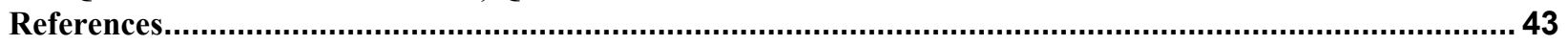




\section{List of Figures}

Figure 1. Household status with respect to consideration and adoption mapped to survey data source 9 Figure 2. Reported levels of trust in PV information provided by various organizations and groups,

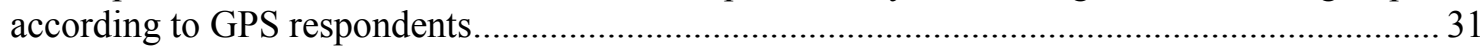

\section{List of Tables}

Table 1. Survey Data Sample Descriptions 6

Table 2. Percentage of PV Adopter (A), GPS-Thought Not Bought (TNB), and GPS-Not Thought (NT) Respondents with Various Characteristics, by State ......................................................... 10

Table 3. Percentage of Respondents in Each Group with Low or High Electricity Bills, All States.......... 11

Table 4. Percentage of PV Adopters with Potentially High-Electricity-Use Items ................................ 13

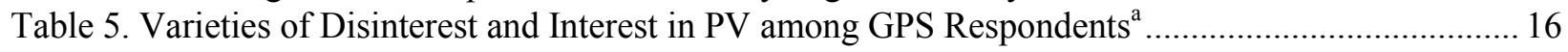

Table 6. Percentage of GPS Groups Potentially Discouraged from PV Installation by Various Concerns and Conditions

Table 7. Comparison of GPS-Not Thought versus Adopter Groups in Terms of Economic Assessment of

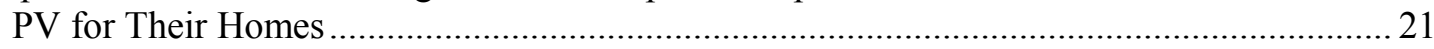

Table 8. Non-Adopter Assessments of Non-Economic, Non-Environmental Aspects of PV ................... 22

Table 9. Strong Adopter Motivations for Considering PV ............................................................... 24

Table 10. Comparing Environmental vs. Economic Motivations of Adopters....................................... 25

Table 11. Percentage of PV Adopters Rating Environmental and Money-Saving Motivations at Various

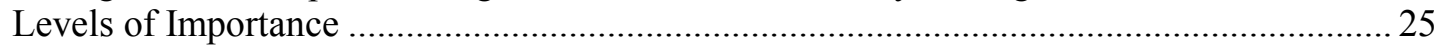

Table 12. Pro- and Non-Environmental Stance by PV Adoption Status ..................................................26

Table 13. Percentage Agreeing to Guilt and Personal Obligation Statements, by PV Adoption Status..... 27

Table 14. Prompts for Considering PV Cited by Adopters.....................................................................2 29

Table 15. Percentages of Considerers Expressing Various Concerns about PV Adoption......................... 34

Table 16. Percentages of Considerers Reporting Various Difficulties Related To PV Adoption................ 35

Table 17. Adopter's Assessments of Actual Payback Time Compared to Expected Payback Time...........36 


\section{Introduction}

Renewable electricity generation has proliferated in the United States and other countries in recent years, and government policies have been encouraging further growth. In the United States, residential rooftop solar photovoltaic (PV) systems are a favored consumer-level route to increased renewable penetration, declining PV prices, government incentives, and third-party ownership options that require little or no upfront investment by the homeowner and have made systems more financially attractive (Drury et al. 2012; Rai and Sigrin 2013). Still, less than 1\% of U.S. single-family households had rooftop PV in 2015. ${ }^{1}$ Penetration levels vary dramatically by locale, but PV "adopters" are still a highly select group.

This report draws on a diverse set of survey data to examine residential PV adoption and nonadoption, the varieties of adopters and non-adopters, and the roles of policies and marketing in shaping these segments. The survey data were collected in three separate streams, according to household PV status: (1) the general population, excluding PV adopters, (2) households that had talked to a PV installer but had not yet installed PV (PV "Considerers"), and (3) PV adopters ("Adopters"). The data set includes survey data from nearly 3,600 single-family, owner-occupied households across four different states: Arizona, California, New Jersey, and New York. Parallel data were collected across the three surveys where applicable. This data-collection strategy, though limited in its suitability for statistical inference enables a wide variety of exploratory comparisons across geography, PV status, and demographic characteristics.

We use these survey data to analyze PV-related experiences, motivations, knowledge, and characteristics of PV adopters, PV considerers, and the general population of owner-occupied households. The results are interpreted through a social scientific lens in the context of current theories and literature about PV adoption. We use the data to identify major storylines without making broader claims about causation or precise population-level estimates. This approach provides a relatively natural view of household PV experiences, in contrast to predictioncentered statistical or simulation-modeling approaches, which generally incorporate implicit assumptions about adoption processes but may miss insights from data that are not or cannot be modeled. ${ }^{2}$ The current report complements the model-centered work that has been completed with these same survey data (Dong and Sigrin 2017; Henry and Brugger 2015; Wolske, Stern, and Dietz 2017).

\subsection{Research Background}

The academic social science literature on renewable energy technology diffusion, household renewables adoption, and renewables use is narrow in scope (Sommerfeld and Buys 2014). Most work on household PV adoption focuses on how to scale initial markets rather than considering more broadly why adoption does or does not occur, or on what happens after adoption. Analyses of PV adoption tend to rest on rational actor economics; psychological notions of attitudes, values, and sentiments; the assumption that PV is fundamentally "about the environment"; or a

\footnotetext{
${ }^{1}$ Based on EIA 861 data retrieved December 2016

${ }^{2}$ In addition, both statistical modeling and inferences from more descriptive approach used in this report depend on sample representativeness, though statistical modeling does so more explicitly.
} 
combination of these framings. Research has often centered on modeling, in which adoption is characterized as an interactive effect of quantified vectors, often along few dimensions, oriented to yielding estimates of statistical effect sizes for various factors.

Despite these limitations in focus, a wide variety of research contributes to the understanding of household PV adoption decisions. Approaches taken include agent-based modeling (Rai and Robinson 2015; Palmer et al. 2015), diffusion of innovations (Faiers and Neame 2006), economic framing (Borenstein 2015; Maloney 2016; Drury et al. 2011), geographic clustering and peer effects (Bollinger and Gillingham 2012; Graziano and Gillingham 2015), environmental values (Chen 2013), improving the breadth of data collection (Caird et al. 2008), sociotechnical transitions (Palm and Tengvard 2011), and sociological attention to the political valences and social context of PV based on household interviews (Schelly 2014, 2015; Sommerfeld, Buys and Vine 2017) or surveys (Simpson and Clifton 2015; Keirstead 2007). There is a longer-running body of work on residential microgeneration in general, particularly covering biomass and solar thermal (Balcombe et al. 2013; Labay and Kinnear 1981; Ornetzeder 2001). Less research has focused on what happens in households after PV is installed; exceptions include Schelly's work on PV adopters $(2014,2015)$ and several studies investigating how energy use changes postinstallation (e.g., Keirstead 2007; Rai and McAndrews 2012).

It might be expected that the large literature on consumer energy efficiency choices would inform social science analysis of PV adoption (e.g., Stern et al. 2016). However, relatively little of that research focuses on major home retrofits, which are most similar to PV adoption. Differences in the costs, visibility, and other technology characteristics of energy efficiency upgrades as compared to rooftop PV complicate comparisons. From a policy perspective, both energy efficiency and PV adoption are typically seen as household investments that reduce the cost of energy services while benefitting the environment. From a homeowner's perspective, however, generating electricity may often be much different than saving energy through efficiency upgrades. PV is more "productive," more visible, less uncertain, usually larger in scale, and usually more highly incentivized. Efficiency upgrades, in turn, often have palpable non-energy effects in the home (such as comfort and functional differences), in contrast to PV, which is largely a different source of the functionally non-differentiated product of electricity, albeit with a different cost structure.

A modest body of research, including some of the modeling studies above has investigated the characteristics of individuals and households who install PV. Most of these studies collect data from PV adopters, sometimes with additional non-adopter data from the general population and rarely from people who considered but did not adopt PV (Balcombe et al. 2014; Vasseur and Kemp 2015). Reporting by journalists and industry specialists often covers consumer perceptions of PV and choices (e.g., PV aesthetics and how to convert PV leads into sales), though most often without a statistical or quantitative basis or formal summary of evidence. Our analysis helps fill some of these gaps via analysis of a large and formal, albeit non-statistical set of survey data.

\subsection{What PV Represents}

The first PV-powered residences in the United States were constructed in 1973, about 20 years after the invention of PV cells in 1954 (EERE n.d.). The social interpretations and policy purposes of PV have varied over time and include providing off-grid electricity supply, reducing 
air pollution and greenhouse gas emissions reductions, reducing consumer electricity costs, improving energy security, and contributing to renewable energy generation. These emphases and interpretations will continue to evolve in light of debates about the systemic configurations of electricity supply, pricing, utility roles, environmental politics, and equity, in turn affecting which households install and why.

Governments, environmental organizations, and many adoption-oriented studies have regularly tended to see residential PV as an "environmental" consumer product, reflecting common policy rationales. Recent studies have found that financial benefits of lower electricity costs and expectations of increased home value often dominate (e.g., Balcombe et al. 2013). Schelly (2014) notes that "while it may seem commonsensical to assume that all residential PV adopters are earth-loving environmentalists, this simply may not be the case."

Our informal review of contemporary U.S. residential PV marketing material shows an emphasis on a multitude of alternative, mostly financial, motives - utility bill savings, discounted system installation, generous state-level incentives such as solar renewable energy credits, the value of "taking control" of energy costs and production, and using technology to capture the sun's free energy. In short, PV now appears to be sold primarily as a consumer good delivering primarily personal benefits, especially monetary savings, if often with implicit or explicit environmental associations. Even the non-financial benefits highlighted in marketing often do not focus on greenhouse gas emissions or pollution reductions but rather orient to psychic benefits of producing one's own power, contributing power to the grid, or generic environmental values. As we show below, though most households we surveyed placed some importance to the environmental associations of $\mathrm{PV}$, few said that they prioritized the environmental benefits of adoption over financial benefits. For some - including some PV adopters - the environmental associations of PV were even seen as a negative attribute.

The association of PV with saving money is underscored by the degree and variety of incentives offered to household adopters. Households do make substantial investments in PV systems even without incentives, but survey respondents clearly saw incentives as important to their decision, with some even describing their installations as "free." The point here is not to debate these subsidies, which may be key to jump-starting a longer-term PV market. Rather, from a dataanalysis perspective, the effects of these subsidies are inherently entangled with who adopts PV and why. So, caution is required in translating the adoption dynamics of subsidized PV to those of unsubsidized PV at current prices.

Finally, there is the issue of who adopts PV and why, in terms of demographics, values, and interests. Despite the increasing proportion of moderate-income households that install PV, adoption is still decidedly higher among upper-income households (Borenstein 2015). To increase residential PV penetration and address equity concerns, policy initiatives have included a concerted effort to increase access to PV for middle- and lower-income households, including bolstering community solar, creating partnerships aimed at increasing installation, and instituting 
new financing options. ${ }^{3}$ These initiatives leads to questions about possible changes during the transition from PV's use by early adopters to its use by the vast numbers of U.S. households that do not currently have PV. These non-adopters are often very different from adopters in terms of energy use, financial circumstances, location, demographics, and other factors. What might change about how PV is offered and the information provided about it to suit these nonadopters? What happens in states where PV is not popular today, as PV moves from being unusual to being commonplace, or as the environmental and other benefits of PV shift as electricity supply and demand shifts? To inform these questions, our analysis offers information for a contemporary view of what U.S. households are thinking, saying, and doing with respect to rooftop PV adoption, and it examines some conventional assumptions about PV adoption.

\subsection{Report Organization}

The remainder of the report is organized as follows. Section 2 describes our data and analytical approach. Section 3 details non-adopter and adopter groups and characteristics. Section 4 analyzes the general population of non-adopters. Section 5 examines the consideration and adoption of PV, including what factors motivate and inhibit adoption. Section 6 discusses experiences PV adopters reported after installation of their PV systems. Section 7 provides a summary of our findings, and Section 8 offers questions about PV's future as well as questions specifically geared toward future research.

3 The White House, "Increasing Solar Access for All Americans," July 7, 2015, https://www.whitehouse.gov/blog/2015/07/07/increasing-solar-access-all-americans 


\section{Data and Analytical Approach}

This section describes the data collection and analysis methods, and concludes with a roadmap of the report's results.

\subsection{Survey Data Collection}

The research team fielded surveys to three different groups of single-family homeowners based on homeowner status with respect to PV: the General Population Survey (GPS) group, or households that had not adopted PV; households that actively considered getting rooftop PV for their current home, but had not installed it (Considerer Survey); and households that had installed rooftop PV on their current homes (Adopter Survey). To compare regional markets at different levels of development and different market structure, the surveys were conducted in four states: Arizona, California, New Jersey, and New York. This resulting data was used to develop agent-based models of PV adoption, which simulated the effects of household demographic characteristics, social influences, financial circumstances, and attitudes and beliefs about the environment, PV, and energy use on PV adoption (see Henry and Brugger 2015; Rai and Henry 2016). Considerer and Adopter survey respondents were asked to report their average winter and summer electricity bills, motivations for considering PV, and other experiences in their consideration, decision, and (for Adopters) installation. The surveys also collected openended comments on respondents' thoughts about and experiences with PV. This report focuses on some of the less model-friendly data collected in these surveys, including the open-ended comments.

The three surveys were conducted between June 2014 and April 2015. Table 1 summarizes the sampling details. Samples were drawn from a combination of paid respondents (i.e., panelists recruited through a web panel company) and, for the Considerer and Adopter surveys, voluntary respondents identified from installer and lead-generator contact lists obtained from companies that collaborated on the research project. In the Adopter sample, $71 \%$ of respondents lived in California, reflecting the market focus of installers who shared their contact lists as well as California's dominance in PV installations. A minimum of 100 responses per state were collected. The panelist responses in the GPS and Considerer samples were distributed fairly equally across the four states, whereas the Considerer lead-generator and installer responses were weighted more heavily toward California and New York. Thus, data collection involved different types of populations (i.e., four states and three different statuses with respect to PV) as well as different sampling frames across, and sometimes within, populations. This was necessary given the nature of the questions and normal resource limits for sampling costs. It renders the data statistically complex and thus limits the ability to make statistical inferences, especially for the Considerer and Adopter populations. ${ }^{4}$

In addition to these household surveys, the research team conducted 72 interviews with professionals from PV installation companies, who were selected to provide a relatively

\footnotetext{
${ }^{4}$ For example, though post-hoc sample weights could be developed, the Considerer and Adopter survey respondents are still drawn from a convenience sample.
} 
comprehensive and diverse sample of installers in the four states. These interviews talked to the installers as experts about PV adoption, asking for their perceptions of customer views on PV, customer decision processes, referrals and leads, and other market issues. We use insights from some of this interview data below.

Table 1. Survey Data Sample Descriptions

\begin{tabular}{|c|c|c|c|c|c|c|c|c|}
\hline \multirow[t]{2}{*}{ Survey } & \multirow[t]{2}{*}{$\begin{array}{l}\text { Recruitment } \\
\text { Source }\end{array}$} & \multirow[t]{2}{*}{$\begin{array}{l}\text { When } \\
\text { Fielded }\end{array}$} & \multirow[t]{2}{*}{$\begin{array}{l}\text { Response } \\
\text { Rate }\end{array}$} & \multicolumn{5}{|c|}{$\begin{array}{l}\text { Responses Passing Data-Quality } \\
\text { Checks }\end{array}$} \\
\hline & & & & $A Z$ & CA & NJ & NY & Total \\
\hline GPS & Panelists & $\begin{array}{l}\text { June/July } \\
2014\end{array}$ & N/A & 351 & 338 & 315 & 337 & 1,341 \\
\hline \multirow[t]{2}{*}{$\begin{array}{l}\text { Considerers } \\
\text { (non-adopters) }\end{array}$} & $\begin{array}{l}\text { Lead } \\
\text { generators, } \\
\text { installers }\end{array}$ & $\begin{array}{l}\text { Dec } 2014 \text { to } \\
\text { April } 2015\end{array}$ & $1.4 \%$ & 13 & 90 & 9 & 41 & 153 \\
\hline & Panelists & March 2015 & N/A & 100 & 97 & 98 & 141 & 436 \\
\hline \multirow[t]{3}{*}{ Adopters } & Installers & $\begin{array}{l}\text { Dec } 2014 \text { to } \\
\text { April } 2015\end{array}$ & $8.5 \%$ & 34 & 1,181 & 185 & 187 & 1,587 \\
\hline & Panelists & $\begin{array}{l}\text { March/April } \\
2015\end{array}$ & N/A & 75 & 0 & 0 & 0 & 75 \\
\hline & & & Total $^{\mathrm{a}}$ & 573 & 1,706 & 607 & 706 & 3,592 \\
\hline
\end{tabular}

${ }^{a}$ The actual number of households surveyed was more than 3,600; data-quality checks (primarily eliminating respondents who failed attention-check criteria) reduced the number of responses used in the analysis.

\subsection{Analyzing the Survey Data}

This report takes a non-modeling, non-statistical approach to data analysis. ${ }^{5}$ Considerable insight can be gleaned by asking who is and who is not interested in or actively adopting PV, and then analyzing the characteristics of these groups. In addition, our analyses do not focus on prediction, in part because adoption and non-adoption (perhaps especially at this early stage of diffusion) are likely sensitive to an intricate and changing set of conditions and concepts about $\mathrm{PV}$ rather than a more deterministic process. The economics of PV will continue to shift due to factors such as changes in incentive levels, PV and installation costs, and electricity tariffs.

Decisions to adopt PV can hinge on a constellation of detailed considerations difficult to capture via a survey or integrate into a regression-based model, even with large samples. For example, considering just the economics of adoption decisions, Borenstein (2015) points to the intricacies

\footnotetext{
${ }^{5}$ Some of the data collected are not suitable for regression modeling, but still provide insight if carefully analyzed and summarized. Furthermore, decision dynamics are complex in relationship to the limited sample size, forcing a relatively simple statistical model. And as noted above it would be difficult, at best, to fairly assign sampling weights, with the possible exception of the General Population Survey. For discussion of some of the shortcomings of incorrectly applying statistical techniques to social data and non-statistically sampled data, see, e.g., Freedman (1991), Freedman (2008), and Smith (1983).
} 
of assessing the private net benefits of PV, which depend on tax advantages, complex tariffs, and various incentives. Other economic circumstances (e.g., bundling with roof upgrades, who in the household pays), in addition to many non-economic issues, complicate the precision of household-level decision modeling that can be achieved. And some economic aspects may be interpreted non-economically (e.g., if incentives are considered a "call to action" or endorsement from the government).

Our analysis emphasizes segments, clusters, and variety while providing summaries of central tendencies. Given the complexity of PV adoption factors - and the diversity of contexts and circumstances even just among single-family, owner-occupied households - taking variety seriously can help draw a clearer picture of where and how PV fits, does not fit, or might eventually fit for individual homeowners and in the residential electricity landscape overall. Our analysis also interprets the "small data" (Lindstrom 2016) from the open-ended survey comments, taking these comments offered by respondents as valuable non-statistical evidence.

\subsection{State Differences}

The four-state data-collection approach was designed to cover a broad geographic range and establish how markets and PV adoption decisions differ depending on the circumstances, trends, and cultures that vary with geography and market development. The histories of PV and PV markets are different in all of these states.

Although this report does not detail these state histories, it recognizes that relationships among the various "factors" (i.e., measured survey variables) may be different across states, in a way that does not reduce to a "fixed effect" in terms of a regression model. In addition, there are many unmeasured variables, such as the shifting political dimensions of solar, the details of incentive structures, the particular utilities at play and ongoing debates about tariffs, the nature of the housing stock, and so forth. Overall, the data reveal both similarities and differences across the four states. To avoid an overly complex presentation of results, however, most results are aggregated across the four states, with some notable state-level differences highlighted. ${ }^{6}$

\footnotetext{
${ }^{6}$ As noted in Section 2.1, sampling strategies differed by states for the Considerer and Adopter surveys; these differences can also contribute to the observed differences across states as well as the particularities of the sample.
} 


\section{Non-Adopter and Adopter Groups and Characteristics}

Most studies of PV diffusion and adoption focus on the characteristics of adopters, sometimes using various types of non-adopters as contrast. Even in California only roughly $5 \%$ of owneroccupied, single-family households had rooftop PV as estimated in early $2016 .{ }^{7}$ Penetration rates are lower in New Jersey and New York than in California and Arizona, and there are hot spots and cold spots within states, but nationwide less than $1 \%$ of households had rooftop PV systems. Within Everett Rogers' Diffusion of Innovations framework (2010), which is commonly invoked in discussing PV adoption, the United States as a whole is still in the "innovators" (first 2.5\%) or "early adopter" (next 13.5\%) phase, depending on how eligibility for adoption is defined. The point here is not to integrate the Diffusion of Innovations framework into the analysis, but to note that "next adopters" may be different than current adopters (Sigrin et al 2015). To better delineate the types of non-adoption, we split "non-adopters" into three different groups, which can each be contrasted with the adopter group in different ways.

\subsection{Analysis Groups}

The populations represented by the three different surveys can be interpreted as falling into one of four statuses with respect to PV exposure, as sketched in Figure 1. PV adopters, who have had PV installed on their current home or signed a contract with an installer to do so, are represented by the Adopter survey. Those who have given at least somewhat serious consideration to installing PV on their current home, but who had not installed at the time of the survey, were recruited for the Considerer survey. The general population of single-family households that have not installed PV is represented by the GPS. GPS respondents were queried about whether they had considered PV for their home but not for the seriousness of their consideration. Likely some GPS respondents considered PV seriously - in particular those who had already talked to an installer - and could have qualified for the Considerer survey. Thus, the Considerer and GPS populations overlap, as depicted in Figure 1.

\footnotetext{
${ }^{7}$ Based on the Energy Information Administration's Form EIA-861 data.
} 


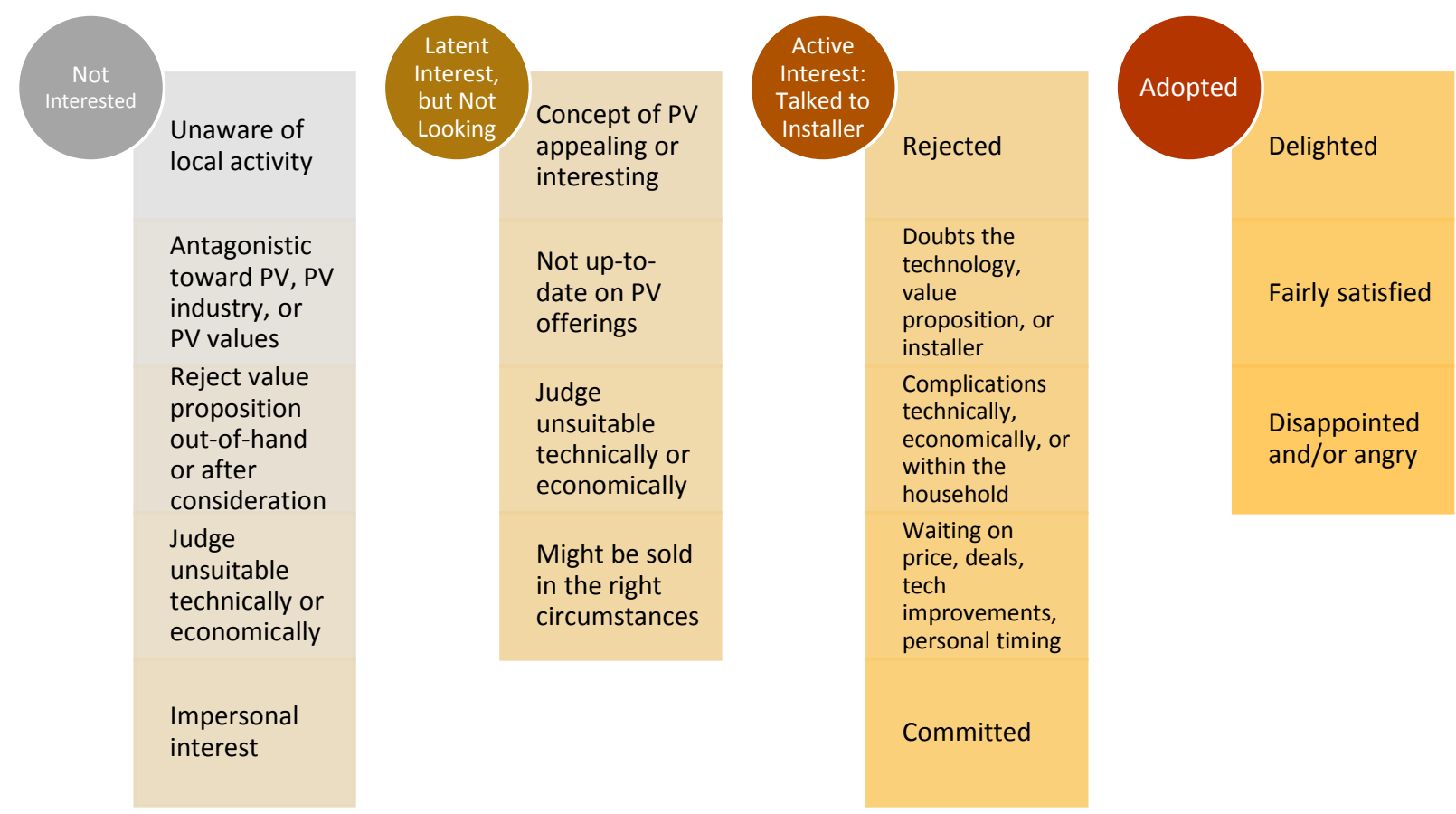

Figure 1. Household status with respect to consideration and adoption mapped to survey data source

The GPS included questions about interest, experience, and plans with respect to installing PV. Over the four states, $37 \%$ of GPS respondents said they had not thought about installing PV on their homes; these are called the "GPS-Not Thought" group. This leaves $63 \%$ in a "GPS-Thought Not Bought" group, consisting of GPS respondents who said they had thought about PV for their homes. Nine percent of GPS respondents who said they had seriously considered PV also said they had already talked to an installer, making them the most similar to the Considerer survey respondents. Most of the GPS respondents who had talked to an installer but not adopted it had no near-term plans to talk to an installer again ( $8 \%$ of the total GPS population). This group might be considered as having "rejected PV" for the time being. Varieties of interest and noninterest are discussed further in Section 4. Comparing survey responses from the GPS-Not Thought group to those from the GPS-Thought Not Bought group suggests where, how, and why $\mathrm{PV}$, as perceived, does not appeal to the general population. Comparing the GPS-Thought Not Bought group with those who have installed PV (Adopter survey) and to more serious considerers who have not (Considerer survey) indicates which conditions and characteristics favor or inhibit PV adoption.

\subsection{Basic Comparison of Group Characteristics}

$\mathrm{PV}$ adoption is rare, so we would expect the characteristics of $\mathrm{PV}$ adopters to be quite different from those of the rest of the population. Table 2 provides an aggregate profile of Adopters ("A" in the table) in terms of simple demographic, social, and energy-use characteristics and compares them to similar characteristics for the two GPS respondent groups, GPS-Not Thought ("NT") and GPS-Thought not Bought ("TNB"). Differences between these groups can provide clues about $\mathrm{PV}$ consideration and decision processes. Many of the patterns in these variables echo those found in Balcombe et al.'s (2013) review of literature on motivations and barriers to residential microgeneration. For the most part, the results confirm what would be expected: overall, 
Adopters have higher electricity bills and more education than GPS respondents. Arizona aside, Adopters are more likely to have income over $\$ 150 \mathrm{~K} /$ year than GPS respondents. Arizona is exceptional in some demographic respects. ${ }^{8}$ There, Adopters are much more likely to be retirees and overall have lower income than in the other states, though this does not necessarily mean they have lower net wealth.

Table 2. Percentage of PV Adopter (A), GPS-Thought Not Bought (TNB), and GPS-Not Thought (NT) Respondents with Various Characteristics, by State

\begin{tabular}{|c|c|c|c|c|}
\hline & Arizona & California & New Jersey & New York \\
\hline $\begin{array}{l}\text { Electricity bill } \\
\text { average } \\
\$ 100 / \text { month or less }\end{array}$ & $\begin{array}{l}12 \% \text { A } \\
13 \% \text { TNB } \\
21 \% \text { NT }\end{array}$ & $\begin{array}{l}14 \% \text { A } \\
38 \% \text { TNB } \\
58 \% \text { NT }\end{array}$ & $\begin{array}{l}21 \% \text { A } \\
20 \% \text { TNB } \\
28 \% \text { NT }\end{array}$ & $\begin{array}{l}19 \% \text { A } \\
26 \% \text { TNB } \\
40 \% \text { NT }\end{array}$ \\
\hline $\begin{array}{l}\text { Summer or winter } \\
\text { electricity bill } \\
\text { average above } \\
\$ 275 / \text { month }\end{array}$ & $\begin{array}{l}39 \% \text { A } \\
28 \% \text { TNB } \\
15 \% \text { NT }\end{array}$ & $\begin{array}{l}43 \% \text { A } \\
14 \% \text { TNB } \\
6 \% \text { NT }\end{array}$ & $\begin{array}{l}36 \% \text { A } \\
28 \% \text { TNB } \\
18 \% \text { NT }\end{array}$ & $\begin{array}{l}31 \% \text { A } \\
15 \% \text { TNB } \\
11 \% \text { NT }\end{array}$ \\
\hline $\begin{array}{l}\text { Household income } \\
\text { over } \$ 150 \mathrm{~K}\end{array}$ & $\begin{array}{l}9 \% \text { A } \\
10 \% \text { TNB } \\
12 \% \text { NT }\end{array}$ & $\begin{array}{l}25 \% \text { A } \\
11 \% \text { TNB } \\
14 \% \text { NT }\end{array}$ & $\begin{array}{l}23 \% \text { A } \\
17 \% \text { TNB } \\
11 \%, \text { NT }\end{array}$ & $\begin{array}{l}27 \% \text { A } \\
18 \% \text { TNB } \\
13 \% \text { NT }\end{array}$ \\
\hline $\begin{array}{l}\text { Household income } \\
\text { under } \$ 75 \mathrm{~K}\end{array}$ & $\begin{array}{l}53 \% \text { A } \\
54 \% \text { TNB } \\
44 \% \text { NT }\end{array}$ & $\begin{array}{l}28 \% \text { A } \\
37 \% \text { TNB } \\
52 \% \text { NT }\end{array}$ & $\begin{array}{l}27 \% \text { A } \\
30 \% \text { TNB } \\
32 \% \text { NT }\end{array}$ & $\begin{array}{l}23 \% \text { A } \\
43 \% \text { TNB } \\
48 \% \text { NT }\end{array}$ \\
\hline $\begin{array}{l}\text { Respondent sex (\% } \\
\text { female) }\end{array}$ & $\begin{array}{l}45 \% \text { A } \\
61 \% \text { TNB } \\
63 \% \text { NT }\end{array}$ & $\begin{array}{l}36 \% \text { A } \\
58 \% \text { TNB } \\
59 \% \text { NT }\end{array}$ & $\begin{array}{l}33 \% \text { A } \\
57 \% \text { TNB } \\
70 \% \text { NT }\end{array}$ & $\begin{array}{l}36 \% \text { A } \\
50 \% \text { TNB } \\
64 \% \text { NT }\end{array}$ \\
\hline$\%$ Retired & $\begin{array}{l}51 \% \text { A } \\
32 \% \text { TNB } \\
56 \% \text { NT }\end{array}$ & $\begin{array}{l}37 \% \text { A } \\
28 \% \text { TNB } \\
50 \% \text { NT }\end{array}$ & $\begin{array}{l}30 \% \text { A } \\
30 \% \text { TNB } \\
41 \% \text { NT }\end{array}$ & $\begin{array}{l}34 \% \text { A } \\
28 \% \text { TNB } \\
43 \% \text { NT }\end{array}$ \\
\hline$\%$ Over age 50 & $\begin{array}{l}84 \% \text { A } \\
60 \% \text { TNB } \\
81 \% \text { NT }\end{array}$ & $\begin{array}{l}71 \% \text { A } \\
58 \% \text { TNB } \\
80 \% \text { NT }\end{array}$ & $\begin{array}{l}65 \% \text { A } \\
61 \% \text { TNB } \\
69 \% \text { NT }\end{array}$ & $\begin{array}{l}66 \% \text { A } \\
60 \% \text { TNB } \\
78 \% \text { NT }\end{array}$ \\
\hline $\begin{array}{l}\text { Have children at } \\
\text { home }\end{array}$ & $\begin{array}{l}15 \% \text { A } \\
23 \% \text { TNB } \\
8 \% \text { NT }\end{array}$ & $\begin{array}{l}30 \% \text { A } \\
27 \% \text { TNB } \\
9 \% \text { NT }\end{array}$ & $\begin{array}{l}43 \% \text { A } \\
31 \% \text { TNB } \\
16 \% \text { NT }\end{array}$ & $\begin{array}{l}32 \% \text { A } \\
31 \% \text { TNB } \\
14 \% \text { NT }\end{array}$ \\
\hline $\begin{array}{l}\text { Education above } \\
\text { bachelor's degree }\end{array}$ & $\begin{array}{l}32 \% \text { A } \\
16 \% \text { TNB } \\
9 \% \text { NT }\end{array}$ & $\begin{array}{l}26 \% \text { A } \\
20 \% \text { TNB } \\
17 \% \text { NT }\end{array}$ & $\begin{array}{l}29 \% \text { A } \\
25 \% \text { TNB } \\
16 \% \text { NT }\end{array}$ & $\begin{array}{l}32 \% \text { A } \\
22 \% \text { TNB } \\
23 \% \text { NT }\end{array}$ \\
\hline
\end{tabular}

\footnotetext{
${ }^{8}$ In the case of the Adopter population, this may be partly due to the sampling frame, which was primarily panelists, versus the installer customer lists used for the other states; see Table 1.

${ }^{9}$ Both average summer bills and average winter bills were less than $\$ 100 /$ month.
} 
As to electricity bills, 31\%-43\% of Adopters reported average summer or winter electricity bills over $\$ 275 /$ month prior to installing PV. GPS respondents with average bills over $\$ 275 /$ month were also more likely to have thought about installing PV $(14 \%-28 \%)$ than not $(6 \%-18 \%){ }^{10}$ Households that leased PV had lower bill levels than those that purchased (not shown in table), but the differences were modest.

Anecdotally, installers are said to target households with electricity bills above certain thresholds (e.g., $>\$ 100 /$ month). The logic is that customers with higher bills have larger electrical loads, and thus greater potential for utilizing solar generation for their direct use. Additionally, for tiered retail electricity plans, solar generation offsets electricity at a higher marginal value. However, not all of the Adopter households that we surveyed had high bills. In Arizona and California, 12\%-14\% of Adopters reported average monthly summer and winter electricity bills of $\$ 100 /$ month or less prior to installing PV; in New York and New Jersey, $19 \%-21 \%$ of Adopters reported the same. Table 3 aggregates results across states to compare the percentages of respondents with low and high summer bills among each group. Low electricity bills clearly make considering or adopting PV less interesting, while high bills seem to make it much more interesting (as well as more common). If the goal is to increase PV adoption and the diversity of adopters, lower-bill households - which constitute most households - may merit more research and marketing attention. ${ }^{11}$

Table 3. Percentage of Respondents in Each Group with Low or High Electricity Bills, All States

\begin{tabular}{lcc}
\hline & $\begin{array}{c}\text { Average Summer Electricity } \\
\text { Bill Below \$100/Month }\end{array}$ & $\begin{array}{c}\text { Average Summer Electricity } \\
\text { Bill Above \$275/Month }\end{array}$ \\
\hline GPS-Not Thought & $39 \%$ & $6 \%$ \\
GPS-Thought Not Bought & $25 \%$ & $12 \%$ \\
Considerer & $27 \%$ & $25 \%$ \\
Adopter & $16 \%$ & $38 \%$ \\
\hline
\end{tabular}

As to individual and family characteristics, the GPS-Not Thought and GPS-Thought Not Bought groups were similar as to overall levels of educational attainment and income. The GPS-Not Thought group had a relatively high proportion of older homeowners, smaller households (without children), and retired homeowners. Adopters and Considerers were more likely to have children at home than GPS respondents who said they had not thought about PV. While households with children are generally larger and use more electricity than those without, there may be more at play than pure economics. Children not only use electricity, but also may make controlling energy use more difficult than in small households, possibly leading to family

\footnotetext{
${ }^{10}$ For example, of the $46 \%$ of New Jersey General Population Survey respondents with average summer or winter electric bills over $\$ 275 /$ month, most (28\% of the total) said that they had thought about installing PV, while only $18 \%$ of the total had not.

${ }^{11}$ EIA estimates the 2015 average monthly residential electricity bill at $\$ 114 /$ month, based on data collected in Form EIA-861 (see http://www.eia.gov/electricity/sales_revenue_price/pdf/table5_a.pdf); the median bill would be lower (i.e., more than half of households have average electricity bills of less than $\$ 114 / \mathrm{month}$ ). This estimate includes multi-family dwellings as well as the single-family, owner-occupied dwellings that are the subject of our study.
} 
tensions (see, e.g., Barkenbus 2013; Carlsson-Kanyama and Lindén 2007). Reducing the marginal cost of electricity could be seen as alleviating these tensions, though this topic was not directly queried or reflected in the survey data.

Installing PV is typically thought of as a joint household-level decision. The survey results suggest an interesting gender dimension to household adoption and debates within the home. Respondents to the Adopter survey - which asked that household members who were personally involved in PV decisions complete the survey-were much more likely to be male than were GPS respondents. ${ }^{12}$ For example, in New Jersey the representation of females in the Adopter survey was less than half of the representation in the GPS-Not Thought group (Table 2).

Differences were smaller in California and Arizona, where overall adoption levels are higher. Given conventional associations of new technology and big investments as the realms of men, and the presence of solar marketing in hardware stores and other construction-related venues more frequented by men, these patterns might not be surprising. There has been little discussion of the gender dimensions of PV (or even electricity) in work centered in the United States, Europe, and Australia, while in developing countries PV is often associated with women-via decentralization, localization, control, family care, and expected contributions of electricity to easing domestic labor (Munien 2014). "Environmental care" is often gendered female (Merchant 2014) though the environmental aspects of PV are not necessarily the dominant feature in current markets and purchasing decisions (see Section 5). The gender breakdown in our survey responses suggests that women could be an under-tapped market for PV.

Adopters were also queried about whether they had any of several items with potentially high electricity use: air conditioning, pools, and electric vehicles. ${ }^{13}$ These results are shown in Table 4.

\footnotetext{
${ }^{12}$ For household surveys in general, women are more likely to respond than men. This was the case in the GPS survey, which had approximately $60 \%$ female respondents. The Considerer and Adopter surveys were sampled differently from the GPS survey, so the contributions of sampling to the observed gender differentials cannot be completely disentangled from differences in interest between men and women.

${ }^{13}$ The survey asked, "Which of the following do you have? 1-Swimming Pool; 2-Air Conditioning; 3-Plug-in electric vehicle; 4-Hybrid vehicle, 5-None of the above." The question did not specify whether the air conditioning was central air conditioning, nor if the electric vehicle was a car (as opposed to another plug-in vehicle such as a golf cart or wheelchair).
} 
Table 4. Percentage of PV Adopters with Potentially High-Electricity-Use Items

\begin{tabular}{|c|c|c|c|c|}
\hline & Arizona & California & New Jersey & New York \\
\hline Have air conditioning $^{a}$ & $83 \%$ & $95 \%$ & $93 \%$ & $85 \%$ \\
\hline Have pool ${ }^{\mathrm{a}}$ & $32 \%$ & $37 \%$ & $26 \%$ & $33 \%$ \\
\hline Have plug-in electric vehicle & $9 \%$ & $6 \%$ & $2 \%$ & $4 \%$ \\
\hline $\begin{array}{l}\text { Do not have pool, } \mathrm{AC} \text {, hybrid } \\
\text { vehicle, or electric vehicle }\end{array}$ & $3 \%$ & $9 \%$ & $6 \%$ & $10 \%$ \\
\hline
\end{tabular}

${ }^{a}$ The survey asked whether the respondent had air conditioning, rather than specifying central air conditioning. Based on our analysis of the RECS 2009 microdata (EIA 2009), the levels of central air conditioning for single-family, owner-occupied households in 2009 were $89 \%$ (Arizona), $54 \%$ (California), 49\% (New Jersey), and 36\% (New York).

${ }^{b}$ These pool saturations are very high compared to those for single-family, owner-occupied homes in the RECS 2009 microdata (EIA 2009). The survey did not ask whether the pool was heated. According to the RECS 2009 microdata, pools are rarely heated with electricity; the maximum across these states is for Arizona ( $5 \%$ electricity). Pool pumps can use considerable amounts of electricity. A report for EIA on miscellaneous electricity use estimated the 2011 Unit Energy Consumption for pool pumps at 2,460 $\mathrm{kWh} /$ year (EIA 2013); this is $\$ 320 /$ year assuming an average electricity price of $\$ 0.13 / \mathrm{kWh}$.

For some households, these particular electric end uses may be an entrée to PV, especially electric vehicles (Rai et al 2016). Even if they did not currently have an electric vehicle, some Considerers and Adopters mentioned that they were planning to buy one and that their consideration of PV was linked to that plan. The open-ended comments demonstrate some of this texture. One survey respondent commented:

\section{If I get an electric car in the future, I will definitely get solar.}

Though actual costs will vary widely depending on electricity rates and mileage, the annual cost for charging an electric car is about $\$ 320 /$ year, which amounts to $\$ 27 / \mathrm{month}^{14}$ The actual economics of adding PV to accommodate an electric vehicle are not necessarily compelling for a given household, but households may be making a different type of connection, perhaps reflecting the widespread policy interest in syncing electric vehicles and PV (see, e.g., Denholm et al. 2013; Rai et al. 2016), or simply identifying electric vehicles strongly with electricity and its costs because it is a high-profile and explicitly "electric" technology.

Some Adopters highlighted prompts to installation beyond the standard "our bills are high" argument; for example, because of specific end uses:

It was the swimming pool pump that got me to install solar. We live in a very mild climate and don't use heating or cooling.

or sudden spikes in bills:

\footnotetext{
${ }^{14}$ This estimate is based on a unit energy consumption of 2,520 $\mathrm{kWh} /$ year and the average residential electricity price in 2015 as reported in Form EIA-861 (EIA 2016).
} 
My decision to go solar was based on a couple of huge utility bills that were never explained.

This report is available at no cost from the National Renewable Energy Laboratory at www.nrel.gov/publications. 


\section{PV in the General Population of Non-Adopters}

To understand adoption in the future, non-adopters need to be seen as a much source of information than simply a homogenous baseline contrast to adopters. This section examines characteristics and sentiments of this non-adopting population on their own terms, summarizing differences in how non-adopters say they perceive PV, what they say about their current and potential future interest in PV and how it might depend on changing conditions, and what seems to be missed by current marketing efforts and even technology characteristics. These results can inform potential changes in the way that residential PV is marketed that might increase adoption as well as help ensure that adoption is sufficiently beneficial to those who adopt it, and ideally, in its consequences for those who do not.

\subsection{From Antagonism to Interest: Levels of Interest in the General Population}

Table 5 (next page) summarizes varieties of disinterest and interest among the general population, based on GPS responses to a battery of questions about interest and plans with respect to residential rooftop PV. ${ }^{15}$ Among the $37 \%$ of GPS respondents that constitute the GPSNot Thought group, nearly half seemed unaware of local PV activity. These respondents stated that they had not seen or heard advertising about PV in the past few months, had not received calls, knew no more than one person with PV, had not talked to anyone who had installed PV, and did not know of any friends or neighbors who had installed PV. If active awareness and familiarity with PV is a gateway to considering it, a large proportion of households seem far from this gateway. Others seemed decidedly uninterested (11\% overall) in talking to an installer, in how PV could work for their home, or in learning about the potential savings from PV.

In the middle ground between the GPS-Not Thought and Adopter groups, members of the GPSThought Not Bought group were currently or had previously been interested in adopting PV, but had not done so. Only $11 \%$ of the GPS-Thought Not Bought group had actually talked to an installer, though $22 \%$ said they would be "very interested" in learning how solar could work for their home. Even recognizing that survey respondents may be overstating their interest owing to the context of the survey itself, these results suggest there is a large untapped interest for PV assessment: many households might be waiting for a PV installer to come talk to them. The extent to which "interested" households are actually good leads is an open question.

\footnotetext{
${ }^{15}$ The GPS was intended to represent everybody but PV adopters. Because Adopter households are such a small percentage of single-family, owner-occupied households, the percentages shown in the table also nearly represent the population of all single-family households in these states.
} 
Table 5. Varieties of Disinterest and Interest in PV among GPS Respondents ${ }^{a}$

\begin{tabular}{|c|c|c|c|}
\hline Percentage by Group & $\begin{array}{c}\text { All GPS } \\
\text { Respondents }\end{array}$ & $\begin{array}{l}\text { Not Thought } \\
\text { Responses }\end{array}$ & $\begin{array}{l}\text { Thought Not } \\
\text { Bought Responses }\end{array}$ \\
\hline \multicolumn{4}{|l|}{ Not Interested/Antagonistic } \\
\hline $\begin{array}{l}\text { Not at all interested in talking to } \\
\text { an installer }\end{array}$ & $13 \%-29 \%$ & $11 \%-18 \%$ & $2 \%-11 \%$ \\
\hline \multicolumn{4}{|l|}{ Not at All Interested } \\
\hline $\begin{array}{l}\text { Not at all interested in how solar } \\
\text { can work for my home }\end{array}$ & $13 \%$ & $11 \%$ & $2 \%$ \\
\hline \multicolumn{4}{|l|}{ Unaware } \\
\hline $\begin{array}{l}\text { Have not noticed much about } \\
\text { solar recently }\end{array}$ & $32 \%$ & $17 \%$ & $15 \%$ \\
\hline \multicolumn{4}{|l|}{ Very Interested Personally } \\
\hline $\begin{array}{l}\text { Very interested in how solar could } \\
\text { work for my home }\end{array}$ & $25 \%$ & $3 \%$ & $22 \%$ \\
\hline $\begin{array}{l}\text { Already talked } \\
\text { Have already talked to an installer }\end{array}$ & $11 \%$ & $0 \%$ & $11 \%$ \\
\hline \multicolumn{4}{|l|}{ Plan to Talk } \\
\hline $\begin{array}{l}\text { Plan to talk to installer in next six } \\
\text { months }\end{array}$ & $11 \%$ & $0 \%$ & $11 \%$ \\
\hline
\end{tabular}

a "Have already talked to an installer" is a yes/no question. The other questions were collected on a 5point rating scale, with the upper two ranks ("Agree" and "Strongly Agree") counted as yes and the lower two ranks ("Disagree" and "Strongly Disagree") counted as no; those who answered "neutral" or did not answer are excluded from the percentages. The GPS excluded households that already had installed PV. The rows of the table are not mutually exclusive. For these reasons the percentages do not sum to $100 \%$

\subsection{Perceived Incompatibilities}

To further understand why current non-adopter households might not be interested in installing PV or be able to install it, we combined responses across a set of survey questions to estimate the prevalence of conditions and concerns that might generally discourage installation. Table 6 presents the results, comparing the GPS-Not Thought and GPS-Thought Not Bought groups. In most cases, percentages were similar between these two groups, albeit often slightly higher for the GPS-Not Thought group, as would be expected. These similarities suggest that the itemized concerns and conditions generally did not stop people from thinking about PV for their home. The remainder of this subsection discusses these perceived impediments in more detail, grouped into four clusters of concerns: financial and payback issues, waiting for technology improvements or price reductions, risks and burdens, and social, political, and personal influences. 
Table 6. Percentage of GPS Groups Potentially Discouraged from PV Installation by Various Concerns and Conditions

\begin{tabular}{|c|c|c|}
\hline Concern or Condition & $\begin{array}{l}\text { GPS-Not } \\
\text { Thought }\end{array}$ & $\begin{array}{c}\text { GPS-Thought } \\
\text { Not Bought }\end{array}$ \\
\hline \multicolumn{3}{|l|}{ Financial } \\
\hline Not compelling financially & $66 \%$ & $59 \%$ \\
\hline Cannot afford & $35 \%$ & $27 \%$ \\
\hline Not at all interested in savings & $27 \%$ & $4 \%$ \\
\hline Low bills (average electricity bill under $\$ 100 / \mathrm{mo}$. summer and winter) & $36 \%$ & $24 \%$ \\
\hline \multicolumn{3}{|l|}{ Long-Term Involvement } \\
\hline May not be in home long enough & $57 \%$ & $45 \%$ \\
\hline Age over 75 & $20 \%$ & $13 \%$ \\
\hline \multicolumn{3}{|l|}{ Technical/Pragmatic } \\
\hline Perceive technical conditions to be unsuitable & $24 \%$ & $17 \%$ \\
\hline Think it is better to wait & $41 \%$ & $43 \%$ \\
\hline \multicolumn{3}{|l|}{ Information } \\
\hline Low trust in information sources & $49 \%$ & $28 \%$ \\
\hline \multicolumn{3}{|l|}{ Risks and Burdens } \\
\hline Concerned with maintenance & $19 \%$ & $18 \%$ \\
\hline Perceived as hassle to install & $32 \%$ & $30 \%$ \\
\hline Concerned with damage to roof & $16 \%$ & $15 \%$ \\
\hline Perceive solar as risky & $34 \%$ & $31 \%$ \\
\hline \multicolumn{3}{|l|}{ Social, Political, or Personal } \\
\hline Not aligned w/environmental and/or climate change causes & $27 \%$ & $11 \%$ \\
\hline Embarrassed to have panels visible on roof & $9 \%$ & $5 \%$ \\
\hline Family/friends would not support & $15 \%$ & $8 \%$ \\
\hline
\end{tabular}

\subsubsection{Financial and Payback Issues}

The two most commonly cited impediments to adopting PV involve the nature of the investment. The lack of a compelling financial motivation was noted by $66 \%$ of the GPS-Not Thought group and $59 \%$ of the GPS-Thought Not Bought group. These results are consistent with many other studies on microgeneration adoption (see the review by Balcombe et al. 2013). Further analyses show that the small percentage of respondents who had already talked to an installer were much less likely to claim that PV was not compelling; this could be related to cause (why these respondents decided to talk to an installer) or effect (something the installer said). Incidentally, some Considerers noted that their conversations with installers made them aware of unanticipated expenses or other costs, such as the need to remove trees or problems with the roof that could make installation much more expensive. 
The second most commonly cited impediment was also related to investment, in particular, to hesitations about payback period. The possibility of not being in their home long enough to recoup the benefits of PV was noted by about half of GPS respondents (57\% of the GPS-Not Thought group and $45 \%$ of the GPS-Thought Not Bought group). The average tenure in an owned home is 13 years (U.S. Census Bureau 2016). Simply calculated, a household with that average tenure would garner less than two-thirds of the lifecycle energy savings benefit, home sales value aside. Concern about the impact of a PV system on home value was evident among GPS respondents, who were mixed as to whether PV would increase or decrease the home's value at sale. ${ }^{16}$ Presumably, part of a PV salesperson's work is to frame the economic decision in a way that resonates with a particular household's decision makers, while keeping the equation favorable in terms of choosing to install.

\subsubsection{Waiting for Technology Improvements or Price Reductions}

As shown in Table 6, over $40 \%$ of both GPS groups said they thought it was better to wait for technology improvements or price decreases. Presuming that a relatively aware portion of the public perceives that the value-to-price ratio of residential PV has increased in the past few years, the flip side of this realization could be the expectation that value-to-price conditions will only get more favorable. For Considerers (not shown), expectations about future improvements loomed even larger, with $62 \%$ saying it was better to wait for better technology or lower prices.

Conversely, in a rapidly changing market, those with little or only casual interest in installing PV may not keep up. Some who think the time is not right might be prompted to reconsider if they encounter updated information on current conditions, at least if this information seems trustworthy. As one Adopter commented:

If we had known how much we were going to save, we would have made this decision much sooner. But that information wasn't available.

This comment also points to the difficulty consumers face in reliably assessing pros, cons, and opportunities about PV installation in highly consumer- and sales-focused markets, where the information provided may be seen as more self-interested than trustworthy; issues of trust are explored in Section 5.4.2.

\subsubsection{Risks and Burdens}

Concerns about unknowns, time, hassle, and other stresses of installing were also very common, with little difference between the two groups. These concerns include the hassle factor of installation $(30 \%-32 \%)$, uncertainty about performance $(31 \%-34 \%)$, concerns about maintenance $(18 \%-19 \%)$, and concerns about roof damage $(15 \%-16 \%)$. As public experience with PV continues, some of these concerns could dissipate if peer experiences could be better shared and are positive overall. But, PV's reputation might not be so positive today. One Adopter commented that their household had gleaned a strongly negative perception of PV prior to talking to an installer:

\footnotetext{
${ }^{16}$ For some Adopters, however, concerns about the effect of PV on home value at point of sale were a showstopper (see Section 5.5).
} 
Until we were contacted by an installer, everything we heard about solar was negative. But our experience has been great!

Thus the PV industry faces the challenge of building positive experiences, which can run counter to shorter-term gains, like those made from quick sales or "fly by night" companies, as some survey respondents noted.

Despite the perceived risks that trouble non-adopters, a scan of PV information available on the web suggests that these technical and administrative concerns are not particularly well addressed. Dismissing or not acknowledging problems avoids providing a "worry list" to potential customers. But, households that are risk-aware and risk-averse may be a large proportion of future customers, so it may be useful to treat existing concerns in a balanced and direct fashion rather than ignoring them.

\subsubsection{Social, Political, and Personal Influences}

In academic research, the environmental benefits of rooftop PV are usually thought of as a plus, something that helps sway households to consider PV and install it, even under economic conditions that are not particularly favorable. In open-ended comments, however, some respondents explicitly, and sometimes disdainfully, distanced themselves from the environmental associations of PV that were implicit in the survey instruments:

Many of your questions had nothing to do with solar... global climate change, etc.

And from one PV adopter:

Installation was free. But with higher costs of electricity, my costs are twice what I expected. I am not some stupid environmentalist.

As shown in Table 6, over a quarter (27\%) of GPS-Not Thought respondents indicated that they were not aligned with environmental or climate change causes, versus only $11 \%$ of GPS-Thought Not Bought respondents. Schelly $(2014,2015)$ analyzes discussions with PV adopters in Wisconsin, showing that homeowners have political perceptions of PV that shape installation decisions and the interpretation of PV post-installation. These perceptions might be highly important in understanding PV adoption, even if the decision appears to hinge on engineering and economic characteristics alone. These political perceptions are not necessarily closely linked to party affiliations. ${ }^{17}$ Schelly's 2015 study found that the politics of PV was most strongly linked to the politics of environmentalism, though other political interpretationsdecentralization, fossil fuel-centered "politics-as-usual," and wealth redistribution-were also evident. These politics, entangled with assessments of technical characteristics of the installation and use, ${ }^{18}$ can both encourage and inhibit PV adoption. Our data-collection methods do not allow definitive estimation of how important environmental interpretations of PV were in persuading

\footnotetext{
${ }^{17}$ Political party and other political leanings were collected in the surveys but are not analyzed in this report.

${ }^{18}$ Such technical assessments include, for example, questions that even experts debate, such as the extent to which a particular household's use of PV offsets carbon emissions and which baseline should be used in the comparative calculation.
} 
and dissuading adoption. In terms of attitudes about the environment and climate change, however, the GPS-Thought Not Bought group was similar to Adopters and Considerers (see Sections 5.2 and 5.3). Thus, positive environmental associations for PV may often align with interest in PV but have less effect on whether PV is actually installed.

Modest proportions of households may be deterred from considering or installing PV owing to disagreements in the family or the influence of neighbors and other peers (Table 6). Among the GPS-Not Thought group, 15\% indicated that they thought people in their family or in their social circles would not support their decision to install PV. Social antagonism or skepticism about PV and its politics could be an important deterrent in some social contexts and geographies (Strauss et al. 2013). This is worth stressing, because, in the academic literature, PV is often presumed to have positive associations, such as commitment to environmental sustainability, technical or community leadership, or wealth. The peer-effects literature on rooftop PV adoption focuses on geographic clustering associated with positive (pro-adoption) influences (e.g., Bollinger and Gillingham 2012). However, peer effects can likely work both ways, and anti-PV is also a form of peer effect, as hinted in the survey results and implied in Schelly's work. Individuals interested in PV might be able to convince family members that PV is a good idea; overcoming social censure may be harder and require a broader strategy.

\subsection{Perceptions of PV Economics in the General Population}

Table 7 compares the GPS-Not Thought group versus Adopters (the two most contrasting major groups) in terms of their endorsement of three different financial aspects of PV as well as the generic assertion that "using solar would help meet my family's needs." In terms of the economic proposition of PV, Adopters were far more positive in their assessment than was the GPS-Not Thought group. Although their adoption decision itself suggests Adopters hold a more positive view of PV economics, the differences could also indicate different ways of assessing or framing these economics, as well as the fact that households who have not thought about PV will have at most done impressionistic rather than formal assessment. Many in the GPS-Not Thought group indicated that they thought PV would have positive financial characteristics; for example, $37 \%$ say that PV would help protect them from rising electricity prices. Still, less than half as many judged PV a great investment, whereas two thirds of Adopters endorsed this view. Only $18 \%$ of the GPS-Not Thought group said they thought PV would meet their family's needs. Many said they did not know, and some were clear that it would not. 
Table 7. Comparison of GPS-Not Thought versus Adopter Groups in Terms of Economic Assessment of PV for Their Homes

\begin{tabular}{lcc}
\hline & $\begin{array}{l}\text { Percent of Group Agreeing or Strongly Agreeing } \\
\text { Adtatement }\end{array}$ & $\begin{array}{c}\text { Adopter } \\
\text { "Using solar will help protect my }\end{array}$ \\
$\begin{array}{l}\text { family from rising electricity } \\
\text { prices in the future." }\end{array}$ & $37 \%$ & $87 \%$ \\
$\begin{array}{l}\text { "Installing solar provides a great } \\
\text { return on a family's investment." }\end{array}$ & $17 \%$ & $64 \%$ \\
$\begin{array}{l}\text { "Using solar would save me } \\
\text { money." }\end{array}$ & $27 \%$ & $87 \%$ \\
$\begin{array}{l}\text { "Using solar would help meet my } \\
\text { family's needs." }\end{array}$ & $18 \%$ & $79 \%$ \\
\hline
\end{tabular}

a There were relatively high percentages of "don't know" responses $(9 \%-14 \%)$ for this question.

\subsection{Perceptions of Non-Economic, Non-Environmental PV Attributes in the General Population}

Table 8 (next page) summarizes how non-adopters assessed PV for a selection of non-economic, non-environmental aspects of PV. All but the last row of the table are statements about PV that speak to a level of comfort with, or positive assessment about, the general value or viability of PV for the respondent's home. The GPS-Thought Not Bought group clearly had a more positive assessment of PV than the GPS-Not Thought group. Over half of the GPS-Thought Not Bought group said that they thought PV would protect their family from blackouts (55\%) and would meet their family's needs (72\%). The assumption that rooftop PV usually protects individual homes from blackouts is a misperception, based on the typical electrical configuration in the U.S., but apparently a very common one. Some Adopters, in fact, said that they were surprised and disappointed when they found out that their system did not work during blackouts. Disabusing potential adopters of this notion, in the interest of accuracy and fair information, would presumably reduce proclivity to adopt. Alternatively, improving the ability of PV systems to provide at least some blackout protection at relatively low additional cost to the homeowner could provide a powerful benefit that many current customers expect to receive.

Few respondents claimed that they would be embarrassed by visible PV on their rooftops. Even among those who had thought about PV (GPS-Thought Not Bought), clear social support for adopting PV was mixed. About half said that they thought that people important to them would support their adopting PV, with almost all of the rest (48\% of the total) neither disagreeing nor agreeing. ${ }^{19}$ Among the GPS-Not Thought group, however, only $15 \%$ agreed that people important to them would be in favor of their installing PV (Table 8); as noted above, this perceived social censure is a peer effect that may impede adoption.

\footnotetext{
${ }^{19}$ This figure combines the "don't know" (12\%) and "neutral” responses $(36 \%)$.
} 
Table 8. Non-Adopter Assessments of Non-Economic, Non-Environmental Aspects of PV

\begin{tabular}{|c|c|c|}
\hline & \multicolumn{2}{|c|}{ Percent of Group Agreeing or Strongly Agreeing } \\
\hline & GPS-Not Thought & $\begin{array}{l}\text { GPS-Thought } \\
\text { Not Bought }\end{array}$ \\
\hline $\begin{array}{l}\text { "Using solar would protect my family from } \\
\text { electricity blackouts." }\end{array}$ & $29 \%$ & $55 \%$ \\
\hline $\begin{array}{l}\text { "Using solar panels on my home would help meet } \\
\text { my family's needs." }\end{array}$ & $18 \%$ & $72 \%$ \\
\hline $\begin{array}{l}\text { "Solar panels nowadays have become very } \\
\text { dependable."” }\end{array}$ & $13 \%$ & $35 \%$ \\
\hline $\begin{array}{l}\text { "People who are important to me would be in } \\
\text { favor of installing solar panels." }\end{array}$ & $15 \%$ & $46 \%$ \\
\hline $\begin{array}{l}\text { "I would feel embarrassed to have solar panels on } \\
\text { my roof where others can see them." }\end{array}$ & $\begin{array}{l}9 \%(68 \% \text { disagree or } \\
\text { strongly disagree) }\end{array}$ & $\begin{array}{l}5 \% \text { ( } 81 \% \text { disagree or } \\
\text { strongly disagree) }\end{array}$ \\
\hline
\end{tabular}

a This question yielded high levels of "don't know" responses: $34 \%$ of the GPS-Not Thought and $27 \%$ of the GPS-Thought Not Bought group answered "don't know." 


\section{Consideration and Adoption of PV}

Electrical systems across the United States generally operate reliably and affordably. In discussing household adoption of PV, Zhai and Williams (2012) note, "Electricity is easily available and inexpensive. In fact, it is hard to notice the existence of the power grid." So, why would households choose alternatives from this system? Which households would make such a choice, and what savings are required?

Social scientists argue that technological transitions are not about any objective supremacy of one technology over another (Palm and Tengvard 2011). Accepting a conventional "rational decision-making" vantage point for the sake of argument, the question is less about barriers to installing PV, but rather about the perceived advantages of PV and for whom, where, and why these seem enough to shoulder the costs, risks, effort, and perceived disadvantages and alternatives. This list would include conditions such as the following:

- Electricity bills are perceived as high, and PV offers sufficient savings.

- It is perceived that electricity bills would be high if the household used substantially more energy services than they already do (e.g., if they are normally conservative with central air conditioner use but want to use air conditioning freely, or if they add a major electricity end use such as an electric vehicle).

- Electricity reliability is poor, and PV is perceived to improve this reliability.

- Environmental advantages are perceived.

- A compelling offer, such as large incentives, is appealing.

- Various psychic and social advantages result, such as social capital, pleasure, alleviation of guilt, reduction of household tensions, and feelings of security and/or community.

- Policies or situations make it difficult not to have PV (which is rare currently).

There is a similar list of disadvantages to be weighed against the advantages. To tease out these perceived advantages and disadvantages of $\mathrm{PV}$, we asked Adopter and Considerer survey respondents about their motivations and concerns for considering installing rooftop PV, as well as the difficulties they encountered while considering installation.

In the 1970s through 1990s, the installation of residential PV technologies may have been largely associated with environmental benefits, environmental showmanship, grid independence, energy security, and being on the technological cutting edge. These aspects of PV presumably remain to some extent, but contemporary marketing of residential PV emphasizes energy cost savings. Environmental benefits are sometimes mentioned, but usually vaguely. As one PV company's advertising puts it, "You save money, the earth saves valuable resources. And we all feel less guilty about the way we consume energy in the process." These motives - including saving money or meeting other financial objectives, protecting the environment, assuaging guilt and obligation, gaining security, and taking pleasure - are explored in this section. 
Adopters rated the importance of each of a series of motives for looking into PV on a 5-point scale from "not at all" to "extremely" important. Table 9 shows the percentages of respondents who marked "extremely important" for each of these motives. ${ }^{20}$ For Adopters, lowering total electricity costs was of top importance overall, with 78\% rating it as "extremely important." Far fewer focused on getting a good return on investment (33\%) or adding to the home's market value $(23 \%)$.

Table 9. Strong Adopter Motivations for Considering PV

\begin{tabular}{lc}
\hline Motivations & $\begin{array}{c}\text { Percent of Adopters Responding } \\
\text { "Extremely Important" }\end{array}$ \\
Lowering your total electricity costs & $78 \%$ \\
Protection from rising electricity prices in the future & $62 \%$ \\
Being able to use renewable energy & $50 \%$ \\
Reducing your environmental impact & $43 \%$ \\
Getting a good return on investment & $33 \%$ \\
Being able to use a promising new technology & $30 \%$ \\
Setting a positive example for others in your community & $26 \%$ \\
Adding to the home's market value & $23 \%$ \\
\hline
\end{tabular}

\subsection{Saving Money While Helping the Environment}

Saving money on household energy costs is the most common stated motivation for considering PV among Adopters (Table 9). Saving money could mean lower bills or lower net expenditures on energy than prior to PV, which are fairly easy for individuals to track. Or it could mean spending less than the alternative if other uses have changed (e.g., acquiring an electric vehicle), which is less easy to track. Among Adopters, $62 \%$ said that protection from electricity price increases in the future was an extremely important motivation; this hedging is in part financial but may also often align with other concerns, such as a sense of independence from the control of the utility. Return on investment and especially adding to the home's market value are difficult for individuals to assess.

A much smaller proportion of Adopters rated "reducing your environmental impact" as extremely important (43\%) compared with saving money (78\%), though few rated it as unimportant. Table 10 and Table 11 compare the economic and environmental motivations of Adopters. One third ranked both saving money and reducing environmental impact as extremely important, while $45 \%$ of the total (including $6 \%$ who said that the environment was not an important or only a slightly important motivation) prioritized saving money. Only $9 \%$ prioritized the environment over saving money, and less than $1 \%$ said that only the environment, not saving money, was important.

\footnotetext{
${ }^{20}$ In general, these statements were highly endorsed. In most cases, fewer than $15 \%$ responded with anything less than "moderately."
} 
These stated motives do not necessarily translate to evaluation criteria, but it is clear that reducing environmental impact was rarely the dominant motivation, whereas saving money often was. It is unclear to what degree buyers evaluate the degree of environmental benefits of PV, if at all, or if environmental benefits are just seen as a fixed quality of the technology.

Table 10. Comparing Environmental vs. Economic Motivations of Adopters

\begin{tabular}{ll}
\hline $\begin{array}{l}\text { Relative importance of } \\
\text { "reducing your environmental } \\
\text { impact" vs. "lowering your total } \\
\text { electricity cost" }\end{array}$ & Percent of Adopters \\
\hline Environment and not money & $0 \%$ \\
Environment over money & $9 \%$ \\
\hline Environment and money equal & $45 \%$ \\
Money over environment & $39 \%$ \\
\hline Money and not environment & $6 \%$ \\
\hline
\end{tabular}

Table 11. Percentage of PV Adopters Rating Environmental and Money-Saving Motivations at Various Levels of Importance

\begin{tabular}{llccc}
\hline Importance of... & \multicolumn{3}{c}{ Reducing environmental impact } \\
& & $\begin{array}{l}\text { "Not at all" } \\
\text { or "Slightly" }\end{array}$ & $\begin{array}{l}\text { "Moderately } \\
\text { " or "Very" }\end{array}$ & "Extremely" \\
$\begin{array}{l}\text { Lowering } \\
\text { total } \\
\text { electricity } \\
\text { cost }\end{array}$ & $\begin{array}{l}\text { "Not at all" or } \\
\text { "Slightly" }\end{array}$ & $0 \%$ & $0 \%$ & $0 \%$ \\
& $\begin{array}{l}\text { "Moderately" } \\
\text { or "Very" } \\
\text { "Extremely" }\end{array}$ & $1 \%$ & $12 \%$ & $9 \%$ \\
\hline
\end{tabular}

The pragmatic "relative good" assessment may be key in examining how customers think about the balance between environment and money. In describing the decision to adopt PV, one respondent commented:

We wanted to help the environment while maintaining our lifestyle.

In a sense, for this respondent, vaguely conceptualized environmental benefits associated with PV seem to serve as a (moral) ticket to less guilty consumption and perhaps higher levels of consumption as well. Section 5.3 discusses guilt further.

These results illustrate a tension between the older notion of PV as environmental and resource conserving versus the current marketing focus on PV saving money. A review by Balcombe et al. (2014) presents a similar finding, namely that a "desire [to be environmentally friendly] does not translate to a willingness to pay extra for it." A finances-first evaluation is not inevitable; people make decisions that do not save them money all the time. Rather, framing PV as a mass 
consumer product with the main benefit of saving money encourages consumers to interpret it within this frame. Clearly, different companies highlight different elements of PV, and salespeople may pitch PV to persuade individual clients. Overall, however, the perception that "PV is about saving money," along with a generic assumption that PV is "environmental" in some sense, is cultural rather than natural law.

\subsection{Depth of Environmental Interest, Concern, and Commitment}

Most Adopters endorsed several general environmental values as well as those specific to energy use and renewable energy, whereas a solid proportion did not. We examined the extent to which Adopters characterized themselves as more aligned with environmental values than non-adopters by classifying respondents as "pro-environmental" if they responded positively to at least six of the nine environmental values survey questions and as "non-environmental" if they responded neutrally or negatively to three or more of these variables. ${ }^{21}$ About half of Adopters met this "pro-environmental" criterion, but so too did about half of Considerers and GPS-Thought Not Bought respondents (Table 12). Only $21 \%$ of the GPS-Not Thought group met the "proenvironmental" criterion, implying that environmental concern (or lack thereof) is a screening criterion for seriously considering PV.

The percentage of "non-environmental" respondents was similar among the GPS-Thought Not Bought, Consider, and Adopter groups (11\%-14\%), compared with 27\% for the GPS-Not Thought group. The aforementioned work by Schelly (2014) on Wisconsin PV adopters argues that environmental debates have increasingly positioned PV politically and that this alignment inhibits some households from adopting PV.

Table 12. Pro- and Non-Environmental Stance by PV Adoption Status

\begin{tabular}{lcccc}
\hline & \multicolumn{4}{c}{ Percentage of Group } \\
& $\begin{array}{c}\text { GPS-Not } \\
\text { Thought }\end{array}$ & $\begin{array}{c}\text { GPS-Thought } \\
\text { Not Bought }\end{array}$ & Considerer & Adopter \\
Pro-environmental & $21 \%$ & $47 \%$ & $53 \%$ & $53 \%$ \\
Non-environmental & $27 \%$ & $11 \%$ & $12 \%$ & $14 \%$ \\
\hline
\end{tabular}

\subsection{Pleasure, Protection, Guilt, and Obligation}

Although our results indicate the importance of saving money and protecting the environment to PV-adoption decisions, these motivation categories encompass substantial complexity. For example, financial concerns might be less about economic calculations and more about other issues, including tensions about money (i.e., "How much will the bill be this month if we use air conditioning?" or "What if utility rates keep going up? How can we reduce the arguments in the household about who deserves to use what and when and how energy must be conserved?")

\footnotetext{
${ }^{21}$ In this scheme, not everybody is classified. In particular, cases in which the corresponding responses were neutral ("neither agree nor disagree") or "don't know" are omitted. Also, Adopters may sometimes be more likely to endorse various environmental values after they install PV than they did before - that is, the installation may lead to the endorsement.
} 
Households with PV may also get pleasure out of their installations. Open-ended comments in the Adopter survey show clear signs of this pleasure (e.g., "I love my solar panels."). Our surveys did not directly investigate this possibility, but they did query respondents on attitudes toward topics that may lead to pleasure: a sense of security, family/home protection, financial security, technological or environmental leadership, energy security, climate change mitigation or general environmental protection, financial savvy, fun and interest, independence from the utility, and so on.

Feelings of guilt and obligation may also be at play. Table 13 summarizes the percentage of each of the four groups who agreed that they felt guilty when wasting energy, felt a personal obligation to prevent climate change, and felt a personal obligation to contribute to a renewable energy future. Feeling guilty about wasting energy was the norm, although fewer respondents who had not thought about installing PV felt this way. Feeling guilty about wasting energy is sometimes interpreted as a motivator for "pro-environmental" behavior. ${ }^{22}$

\section{Table 13. Percentage Agreeing to Guilt and Personal Obligation Statements, by PV Adoption Status}

\begin{tabular}{lcccc}
\hline & $\begin{array}{c}\text { GPS-Not } \\
\text { Thought }\end{array}$ & $\begin{array}{c}\text { GPS-Thought } \\
\text { not Bought }\end{array}$ & Considerer & Adopter \\
$\begin{array}{l}\text { "I feel guilty when I waste energy." } \\
\begin{array}{l}\text { "I feel a personal obligation to do my } \\
\text { part to prevent climate change" }\end{array}\end{array} \quad 42 \%$ & $60 \%$ & $68 \%$ & $69 \%$ \\
$\begin{array}{l}\text { "I feel a personal obligation to do my } \\
\text { part to move the country to a } \\
\text { renewable energy future." }\end{array}$ & $32 \%$ & $57 \%$ & $63 \%$ & $62 \%$ \\
\hline
\end{tabular}

Guilt dynamics might be important to perceptions about PV's environmental benefits. In particular, is rooftop PV electricity relatively exempt from concepts of guilt-inducing waste? This situation has implications for estimating greenhouse gas emissions savings from $\mathrm{PV} .{ }^{23} \mathrm{In}$ particular, does cheaper or even "free" (at the margin) electricity encourage higher use? The data collected for this project cannot be used to estimate this possibility. Comments from the Adopter households surveyed, however, hint that this could sometimes happen:

We pay a few dollars a month for connection and have an annual bill of about $\$ 400$. We run the AC all summer long. Everybody in this area should have solar panels.

According to this PV adopter, PV can be a great deal when evaluated on a sunk investment basis. That is, if the energy generated appears to be without environmental consequences and with minimal incremental financial costs, why not use it?

\footnotetext{
${ }^{22}$ See Turaga et al. (2010) for a review of the concept of pro-environmental behavior.

${ }^{23}$ Evidence of the impact of adoption of energy durables on household energy consumption is mixed, and referred in economic literature as the "rebound" or "ripple" effect; see, e.g., Gillingham et al. 2016.
} 
An alternative interpretation of household energy consumption is that households are conserving energy all the time, rather than just choosing desired levels of comfort and convenience, and paying accordingly. For example, many households in warmer areas may reduce air conditioning to save on energy bills or assuage feelings of guilt or personal obligation. Summer energy bills do not necessarily reflect "comfortable" conditions within a home. Thus PV could improve summer comfort more affordably, concretely, and immediately than could energy efficiency upgrades. The energy generated may have substantial advantages in terms of health and comfort for a household but not reduce greenhouse gas emissions or even total energy consumption.

In contrast to the results for guilt about wasting energy, Adopters were much more likely to say that they felt a personal obligation to prevent climate change or to "do [their] part to move the country to a renewable energy future" compared with the GPS-Not Thought group. Thus, feeling a personal obligation to contribute to slowing climate change may encourage adoption, or at least become a rationalization for it. Non-adopters who had considered PV (GPS-Thought Not Bought and Considerer groups) were as likely as Adopters to feel a personal obligation to "do my part to prevent climate change." Adopters were even more likely (79\%) to feel personally obligated to support a renewable energy future. Those who had only thought about installing PV were less likely to say they felt such a personal obligation $(57 \%-65 \%)$, and still fewer $(32 \%)$ of those who had not thought about installing PV stated such an obligation. At least at this early stage of PV diffusion, wanting to support a renewable energy future appears more strongly aligned with adopting PV than are concerns about climate change.

\subsection{Deliberative Decision Styles and Alternatives}

A classic decision-making model for installing PV starts with an initial level of interest based on the perceived value of PV. This leads into a deliberative decision-making process in which the homeowner actively investigates PV - weighing benefits, costs, and risks - and, if an adoption decision is made, deliberates further to choose among various options such as buying versus leasing, system size, timing, installer, and so forth (Faiers and Neame 2006). It is convenient to frame decisions in this deliberative, model-friendly, fashion. Based on our survey data, however, some decisions appeared to fit a deliberative framework, whereas others may have been barely deliberative at all.

Adopters were asked what prompted them to consider PV, using a list of 15 options shown in Table $14 .^{24}$ The most commonly reported prompts involved information seeking or hearing about PV: $79 \%$ of Adopters said they were looking for ways to reduce energy bills, while $63 \%$ had heard it was more affordable, and 23\% had heard about low-money-down options. These responses are consistent with a "deliberative" model of PV adoption, with respondents saying they were initially prompted to consider solar by a perception of the value of PV.

\footnotetext{
${ }^{24}$ The median number of cited prompts was three.
} 
Table 14. Prompts for Considering PV Cited by Adopters

\begin{tabular}{ll}
\hline Prompt & \% of Adopters \\
$\begin{array}{l}\text { Looking for a solution } \\
\quad \text { Looking for ways to reduce energy bills }\end{array}$ & 79 \\
Intrigued by the possibility & 63 \\
$\quad$ Heard it was more affordable & 23 \\
$\quad$ Heard about low-money-down options & \\
Social & 22 \\
$\quad$ Saw advertising or news article & 21 \\
$\quad$ Saw solar being installed on a home & \\
Installer interactions & 54 \\
$\quad$ Approached by an installer & 7 \\
$\quad$ Offered at a retail store, home show, or community event & \\
Planning, events & 10 \\
$\quad$ Planning for retirement & 2 \\
$\quad$ Came in to some money & 2 \\
$\quad$ Had group purchase opportunity & \\
Home changes & 6 \\
$\quad$ Considering a major new energy use & 5 \\
Planning/doing other work on home & 4 \\
\hline Bought a home/moved & 2 \\
\hline
\end{tabular}

On the other hand, many Adopters also stated that coincidental or non-deliberative interactions prompted them to consider PV, including talking with installers; talking within social circles; seeing ads, news, or a new installation; or experiencing household events or circumstances (Table 14). The large fraction of Adopters that were prompted by external influences suggests that, for most Adopters, self-driven interest alone may not have been sufficient to lead to more serious consideration. By implication, many in the GPS-Not Thought group may actually be more amenable to considering PV than might be assumed. So, there may be a large latent interest that can be activated through external influence.

At the opposite extreme from interest-driven consideration were the $20 \%$ of Adopters (primarily leasers) who reported not considering PV before talking to an installer, indicating that "talking to the installer got me interested." 25 That is, many "opportunist" Adopters seized an opportunity provided by their installer, even if it just started by a knock on the door. Sigrin (2015) also discusses such a "sold, not bought" aspect of PV, further discussed below.

\footnotetext{
${ }^{25}$ As shown in Table 14, 54\% said they were approached by an installer. Over half of these indicated that they had been thinking about PV before this approach.
} 
From the perspective of predicting and increasing PV sales, these relatively opportunist segments are interesting. Some households that have adopted PV were "natural" candidates for PV from the economic and technical perspectives, but overall they have been targeted, both directly and indirectly. Policies, instruments, marketing, and technical offerings create adopter niches and voids. Marketing differently could change who buys and even what is offered, just as third-party ownership (TPO) has changed the demographics of adoption.

Social or peer influences on adoption increasingly have been recognized in the literature (see, e.g., Bollinger and Gillingham 2012), and our survey data indicate that this peer effect was often important for prompting consideration. However, installer interactions and influences have often been missed when analyzing PV adoption, although clearly they have not been missed in marketing or "lead generation" practice. Installer influences appear in our results to be of prime importance, and they infiltrate the "social influence" category. For example, in 72 interviews with individuals from PV companies across the four study states, almost all reported incentivizing or at least asking their customers to refer other interested people to them. As noted in Table 5, over half of GPS respondents said they had thought about PV, and, of the GPS respondents who had thought about PV, two thirds said they were interested in talking to an installer but had not yet done so. Thus there is some circularity in assuming that the characteristics of current PV adopters represent a fundamental nature of adopters, rather than reflecting — to some extent-marketing efforts.

\subsubsection{Getting Enough Information}

Installing rooftop PV involves a long-term commitment and often a substantial amount of money, and it comes with complex economic and technical performance considerations. In the context of deliberative decision-making, deciding whether to install PV, and selecting options for the installation, can be highly complex. There is little long-run social experience for residential PV systems and little in the way of performance reviews, such as are available for cars (e.g., Consumer Reports, True Car, and other websites). Utility reactions and tariff arrangements are in a public, sometimes contentious phase of debate in a number of states, with potentially high stakes for households with PV, utilities, and the PV industry. Current net-metering arrangements are not necessarily intuitive. How much electricity the system will generate is uncertain, as are future electricity rates and household electricity use. There are often various types of financial incentives from different layers of government and with varied rules and deadlines. Buying or leasing a car is more straightforward and partially reversible. So, how do households judge the quality of the PV information they are faced with? The perceived trustworthiness of information sources is important.

\subsubsection{Trust}

GPS respondents were asked about how much they trusted various groups and organizations to provide accurate information about residential PV. ${ }^{26}$ As shown in Figure 2, trust in information

\footnotetext{
${ }^{26}$ The actual question was, "To what extent would you trust each of the groups and organizations listed below to provide accurate information about residential solar energy"? While the question asks specifically about information, this might sometimes be conflated with trust of the organization overall.
} 
sources other than friends, family, and neighbors was low. Most respondents said they highly trust the information provided by friends and family ( $75 \%$ trust "quite a bit" or "completely") and neighbors (55\% trust "quite a bit" or "completely"). On the other extreme, trust of the solar industry (installers and trade organizations) was very low, with $12 \%$ of respondents stating that they "do not trust at all" each of these groups. Trust levels were lowest among those who said they had not thought about installing, so a low sense of trust may be a big barrier to even thinking about installing. ${ }^{27}$ Nor did many trust utilities, though that distrust could also be motivation for installing PV. Government and environmental organizations were judged similarly; $23 \%-27 \%$ of respondents stated they trusted these sources "quite a bit" or "completely," and a substantial proportion expressed distrust. There was a cautious level of trust expressed for university researchers, with more than one-third of respondents expressing high trust and few completely distrusting them. Trust levels of particular sources likely depend on knowledge levels, as suggested by a recent study covering the public's view on the trustworthiness of information by fracking by information source (Theodori et al. 2014).

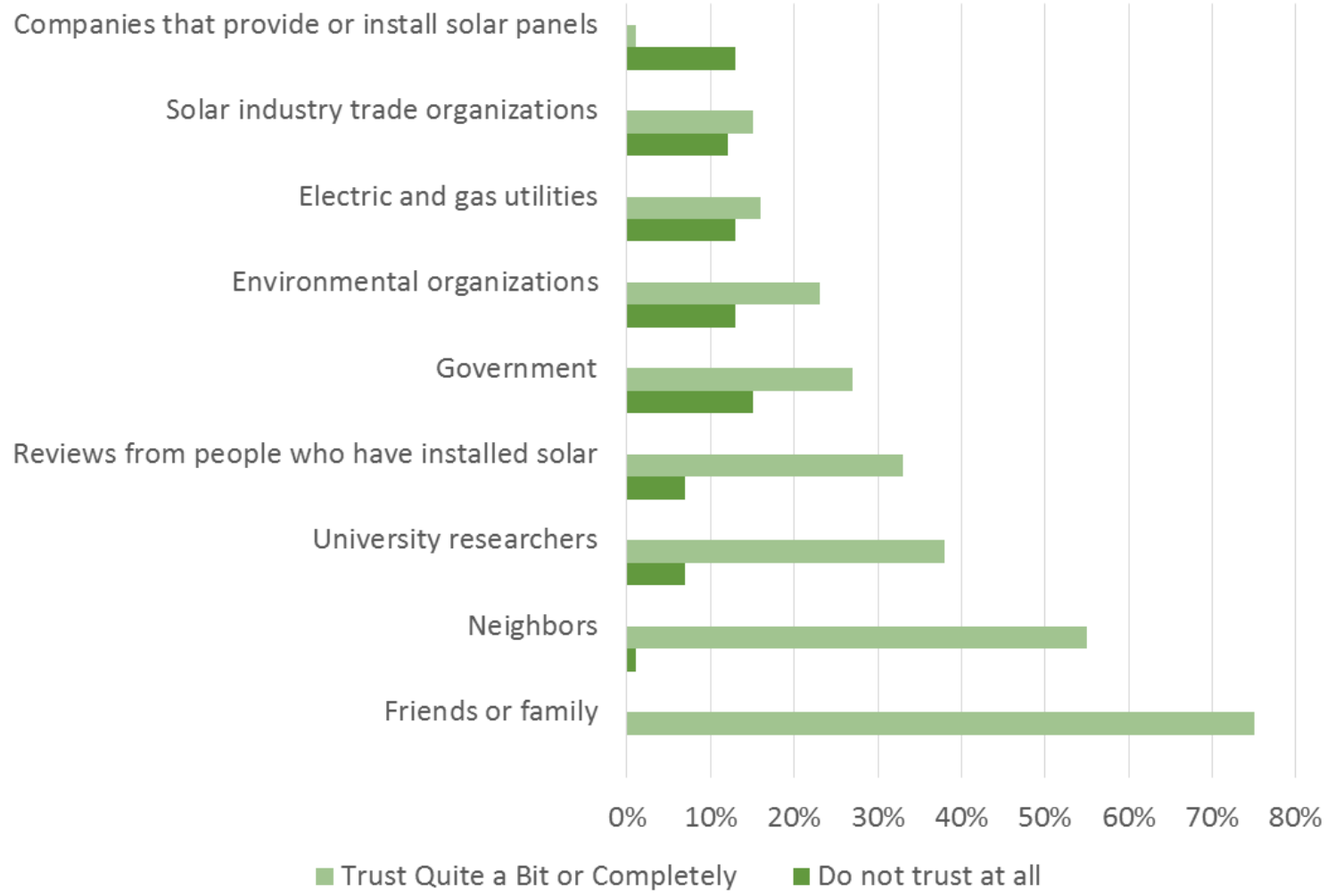

Figure 2. Reported levels of trust in PV information provided by various organizations and groups, according to GPS respondents

Survey respondents often brought up issues of trust and confusion in their open-ended comments. One non-adopter said:

\footnotetext{
${ }^{27}$ Among the GPS-Not Thought group, 20\% said they did not trust installers at all, and 19\% said they did not trust trade organizations at all.
} 
Expensive. Very confusing in regards to lease vs. buy. So many solar companies out there. Do not know who to trust, who is the best value, who will be around for years, or if they are a fly-by-night company. Government incentives are not enough, always change, and have too many deadlines. [Bold added for emphasis]

Another commented:

Contacted a company, received some additional data about them. They had conflicting information about how to install solar on a house with a cement tile roof and sounded like they did not know what they were talking about. Said whole roof would have to be replaced if I got solar. That's incorrect.

The conflicting information adds confusion and may stop or stall customers who would otherwise buy. A 2016 industry survey of installers found that confusion caused by competitors was considered the top challenge in closing sales, lowering consumer confidence (EnergySage 2017); $53 \%$ of surveyed installers considered this to be a problem.

While some respondents said that they had very positive interactions with installers, others were irritated by "constant contact" and sales tactics. Some respondents expressed their skepticism clearly. For example, one Adopter said:

Overall I think the solar companies are dishonest, opportunistic, and unethical.

Several of the installers we interviewed noted this skepticism among potential buyers as well.

Despite low levels of trust noted by the general population (Figure 2), in action, installers are obviously often very influential. How the interactions between households and installers plays out will depend on homeowner decision-making styles (as well as more momentarily varying mood, financial circumstances, etc.) and installer sales style. Adopters reported shopping around less than one might expect given the reported mistrust. Most Adopters (68\%) said they talked to only one or two solar companies, with leasers talking to fewer companies than buyers. Leasing may be less deliberative or simply appear to be a less risky, easier decision. For those who purchased their system outright, more than half $(55 \%)$ reported talking to three or more installers.

As another example of deviations from the deliberative ideal, most Considerers and Adopters did not appear to consider seriously both buying and leasing options. Instead, many seemed to consider only one option, depending on the offerings of the installers they spoke with. Referrals may help explain the lack of shopping around. Thirty percent of Adopters reported having been referred to a particular installer, and most $(84 \%)$ of these referred households selected that installer. This bears out the expectation that referrals from friends, families, and neighbors can be very influential.

At least for a deliberative decision-making path, there is a bind: information from industry sources is not trusted, and there is not enough of it from trusted sources. Recent work in Australia (Simpson and Clifton 2015) and the United Kingdom (Balcombe et al. 2014) emphasizes how difficult some households say it is to find trustworthy information. Our survey respondents sometimes commented that detailed information was hard to find, or that processing it was difficult: 
Actual results would have helped me make my move sooner. Instead we had no such figures.

\section{Very hard to figure out all the options.}

As Owens and Driffill (2008) note in the context of energy efficiency research, information on its own does not automatically transform consumers and their actions. And, as suggested by the juxtaposed quotes just above, having too many choices can also make things more difficult.

Installing PV exemplifies the difficulties of the dilemma of modern consumer choice, where so much information is potentially available that it becomes overwhelming (Broniarczyk and Griffin 2014). PV is not necessarily a good decision for all households. More effort to develop an up-to-date "Buyer's Guide" addressing processes, risks, and doubts could help. Rather than trying to provide customized answers for individual households, this guide could lay out contours of the decision, and provide a "frequently asked questions" section, covering topics such as the reasons for and expected ranges of true-up (net-metering reconciliation) bills, the roles of tariffs, buying and leasing considerations, system options (e.g., size, roof vs. ground mounting), maintenance requirements, the nature of guarantees, and other questions that affect the experience and economics of PV. However, such a guide would also need to incorporate local market nuances, such as incentives offered, building and electrical codes, etc.

In summary, some households may take a deliberative approach to deciding whether to adopt $\mathrm{PV}$, while many appear to act more impulsively or in reaction to sales calls or other opportunities. For the deliberative, constraints on trusted information and social experience, complexity, and uncertainty about the future suggest that satisficing ${ }^{28}$ (Simon 1947) was more common than not. A refined and deliberative decision-making process for PV could be exhausting. For careful decision makers, at least those who are concerned with risk, the effort and uncertainties may stymie adoption. Relatively impulsive buying may be far easier, particularly when the product can be presented in a fashion that leverages decision shortcuts and reduces certain common uncertainties, as appears to be often possible with TPO (e.g., "save $\$ 30 /$ month" vs. "we will save you \$30/month off your current electricity bill, with minimal or no money down, with guaranteed system performance, and we'll do any maintenance necessary"). The next subsection addresses the concerns and difficulties reported by Considerers stalled out in the decision-making process.

\subsection{Stalled or Stopped by Concerns and Difficulties}

What happens to those who seriously consider PV but do not, at least for the time being, install it? As indicated in Figure 1, only 11\% of Considerers said they had rejected PV outright or were

\footnotetext{
${ }^{28}$ Simon proposed the concept of "satisficing" to describe how real-world choices made under intrinsic uncertainty differ from the idealized model of rationality in that available alternatives are searched until an acceptable (nonoptimal) threshold is met.
} 
not currently considering it, ${ }^{29}$ whereas $60 \%$ said they were still considering or undecided, and $23 \%$ said they had decided to install but had not yet acted.

To understand the details of how interest stalled or stopped, the Considerer survey asked about specific concerns that respondents experienced while considering PV. ${ }^{30}$ As shown in Table 15, directly financial concerns - affordability, sufficiency of bill savings ("enough bang for buck"), the wisdom of the financial decision, and the taking on of debt or signing of a lease-were each stopping points for more than half. Concerns about the aesthetics of PV or selling a PV home were the least common, with about half saying they had little to no concern in these regards. Even so, aesthetics and impact on the home's sales value remained bothersome enough to nearly a third of Considerers to stop their consideration of PV. These results underscore what are, in many cases, high uncertainties associated with adopting PV as well as the variety of different circumstances that shape assessment. Economic evaluation itself relies on uncertain assumptions and unfamiliar and potentially transient accounting schemes. Potential savings are not always large, but the commitment to PV is long and essentially irreversible. Societal experience over the long term is still scarce. PV may be perceived as complicating the household's relationship with their utility, and interpretations will depend on each individual's personality and circumstances.

Table 15. Percentages of Considerers Expressing Various Concerns about PV Adoption

\begin{tabular}{|c|c|c|}
\hline How concerned were you about...? & $\begin{array}{l}\text { "Not at All or } \\
\text { Slightly" }\end{array}$ & $\begin{array}{l}\text { "Stopped Consideration } \\
\text { of PV" }\end{array}$ \\
\hline Affordability & $19 \%$ & $58 \%$ \\
\hline $\begin{array}{l}\text { Whether panels offered enough "bang } \\
\text { for buck" }\end{array}$ & $17 \%$ & $50 \%$ \\
\hline Equipment quality and reliability over time & $16 \%$ & $44 \%$ \\
\hline Whether solar was a good financial decision & $18 \%$ & $53 \%$ \\
\hline Taking on debt or signing a lease & $25 \%$ & $55 \%$ \\
\hline Having to perform regular maintenance & $25 \%$ & $37 \%$ \\
\hline Risk of damaging your roof & $30 \%$ & $40 \%$ \\
\hline Might detract from home's "curb appeal" & $49 \%$ & $29 \%$ \\
\hline $\begin{array}{l}\text { Might be harder to sell home with solar } \\
\text { panels }\end{array}$ & $54 \%$ & $30 \%$ \\
\hline
\end{tabular}

\footnotetext{
${ }^{29}$ One third of these respondents said they were at least somewhat likely to reconsider PV within the next 2 years. Recall that Considerer respondents were largely drawn from installers' lists, so the statistics reported here depend on how the installers compose and maintain these lists.

${ }^{30}$ Respondents were asked to select from five levels (not at all/not applicable, slightly, somewhat, very, extremely) for a fixed set of concerns and from five levels (none/not applicable, a little, some, a lot, a great deal) for a fixed set of difficulties. Those who responded positively ("slightly" or "a little" or higher) were asked a follow up yes/no question on whether that issue or concern stopped them from getting PV.
} 
Considerers were also asked about the difficulties they encountered while thinking about installing PV. Their responses are summarized in Table 16. Coming up with enough money to install PV was the top difficulty cited, stopping just over half of respondents from considering installation. Other reasons for stopping consideration included trouble finding trustworthy, competent installers (37\%), technical concerns with home suitability (36\%), disagreements within the household (28\%), finding an installer to do the work $(26 \%)$, and encountering permitting, zoning, or neighborhood restrictions $(22 \%)$.

In summary, some households that considered PV were simply unable to make the proposition work. Perhaps their home was not suitable, electricity bills were too low, their credit rating was insufficient, there was no way they could come up with the money, and so forth. These could be considered "hard stops," at least for the time being. Most Considerers, instead, were hesitating. Half identified at least five concerns and difficulties as having stopped them from adopting. Their interest might be reactivated in the future, and some are still actively considering but delaying action. The number and variety of concerns and difficulties reported suggest that reactivating this group likely would require more than simply asking them to reconsider, absent other changes in arrangements.

Some opportunities for progress are readily apparent. The effect of PV on the sale of a home (see Hoen et al. 2013, for example) or the risk of roof damage are at least subject to empirical examination, which can reduce uncertainty over these issues as evidence builds. Other issues may be addressed in novel product or financial configurations, as in the TPO systems, where responsibility for equipment reliability and maintenance has been shifted from households to PV companies. That shift was often reported as a deciding factor in leasing a system for the subset of surveyed Adopters who also considered purchasing. General societal familiarity and experience with PV will continue to unfold, as will various institutional adjustments (such as changes in incentive design and levels, a settling of utility tariffs, regulations, etc.). The results and perceptions of results will be critical for adoption going forward.

Table 16. Percentages of Considerers Reporting Various Difficulties Related To PV Adoption

\begin{tabular}{lcc}
\hline How much difficulty did you have with ...? & "None or A Little" & $\begin{array}{c}\text { "Stopped } \\
\text { Consideration of PV" }\end{array}$ \\
Coming up with the money to get solar & $35 \%$ & $55 \%$ \\
Finding a trustworthy and competent installer & $36 \%$ & $37 \%$ \\
Suitability of your home site & $43 \%$ & $36 \%$ \\
Finding an installer who would agree to do the work & $58 \%$ & $26 \%$ \\
Permitting, zoning, or neighborhood restrictions & $58 \%$ & $22 \%$ \\
Not everyone in your household being convinced & $62 \%$ & $28 \%$ \\
\hline
\end{tabular}




\section{Experiences Post Installation}

PV Adopters were asked several questions about their post-installation experience. Most had their systems for less than two years and some for only a few months. Overall, reported experiences among survey respondents were good. ${ }^{31}$ Asked whether they had any regrets about installing PV, only 9\% said they had. Regrets were more common among those who had leased their system (11\% stated regrets) than purchased it (5\% stated regrets).

Some PV adopters were enthusiastic about the low-risk, low-upfront cost of their installation, even noting that the deal was so good it was hardly believable:

Absolutely FREE solar panel installation, warranty for 20 years.

With the state payment, federal tax credit, and loan ...this was a no-brainer. It took me two months to believe it.

I tell other people that my panels were free, but nobody believes it.

I can't understand why everybody doesn't do it.

Adopters usually said PV was paying back about as fast (39\%) or even faster (27\%) as than expected, as shown in Table 17. Thus two thirds thought they were getting at least what they expected in terms of financial payback. Only 13\% said that payback was slower or much slower than expected. The rest (21\%) said it was too early to tell or that they did not know.

Table 17. Adopter's Assessments of Actual Payback Time Compared to Expected Payback Time

\begin{tabular}{lc}
\hline Actual Payback Time Compared to Expected & Percent of Adopters \\
Slower or a lot slower than expected & $13 \%$ \\
About as expected & $39 \%$ \\
Faster or much faster than expected & $27 \%$ \\
Too early to tell & $14 \%$ \\
Don't know & $7 \%$ \\
\hline
\end{tabular}

Some respondents expressed disappointment with savings:

Expected better savings, highly disappointed.

A realization that long-term savings were lower than expected could take several years:

For the first two years, we had savings. Then the utility put in a new meter, and our electricity kept going up, $\$ 670$ the first year, then $\$ 950$. And they don't buy electricity from us. The utility is sapping the value of solar. The meter lies.

\footnotetext{
${ }^{31}$ Because this is a convenience sample, the estimates do not necessarily apply to the population of PV adopters at large.
} 
Still, some households that saved less than expected (but still saved something) said they were contented by the environmental benefits:

Although we are saving only half of what we had hoped with solar, it's better for the environment.

This last comment suggests that, though environmental benefits are invisible, the idea of them can provide ongoing value to PV adopters.

Dissatisfied buyers can influence others against PV. Setting up appropriate expectations for PV system performance and savings could reduce the number of dissatisfied customers. Some of the lukewarm comments that Adopters made about their experience with PV may help provide a way forward. For example:

Although I have seen savings, I struggle to understand the breakdown of savings and the reason for a lump sum payment every year.

I am still pleased with the panels, and enjoyed the integrity and expertise of the installers. But I wish it could have been better and more rewarding. I wish I had a professional explain options and ramifications of the investment. Maybe there could be a better way.

But, what would be a better way? More research attention - in particular, in-depth discussions with PV adopters, along with measurement of private and personal financial results and environmental benefits - to household experiences in using PV systems, both good and bad, could provide a useful supplement to the current research focus on buying and selling PV. Given the long expected lifespan of PV, adoption is not the end of the PV cycle, nor should it be the end of the research cycle. This post-installation attention could help ensure that future Adopter experiences are as good as possible and find ways to improve the experience. Are households happy with the installation? How have their electricity bills and electricity use changed? What, if anything, would they do differently? Solar thermal water heating, which in the past has been fairly popular in some locales, has suffered from poor reputation in past installations (StryiHipp 2001). 


\section{Summary}

This report provides a data-based interpretive view of contemporary PV adoption and nonadoption in U.S. single-family households. The report covers attitudes, knowledge, experiences, and assessments of households that have installed rooftop PV, those who seriously considered adopting PV but have not installed it, and the "general population" of households without rooftop PV. This section summarizes our results.

\subsection{Diversity}

Households are never average. Our analyses aim to keep the texture of PV adoption and nonadoption processes rather than generalize by focusing on central tendencies or general relationships. The survey data collected show that motivations, conditions, and experiences related to PV vary widely. Economic conditions are an important component of that variation, but not the only one. For example, some households see the environmental associations of PV as a reason to consider installing it, while others seek to distance themselves from environmental and related political aspects of PV and possibly even avoid considering PV because of them. Some households value the blackout protection that they think PV provides, even though few current installations actually provide such blackout protection - and so on, regarding aesthetics, the importance of resale value, whether installers should be trusted, and the effects of opinions of friends and neighbors, and how economics are assessed. Some Adopters thought installing PV was an easy decision, while others, including those who did not consider PV were put off by assessing its benefits, costs, and uncertainties. Attempts to generalize through statistical models can collapse across this diversity.

\subsection{PV as a Consumer Product}

We have tried to step back from normative assumptions about PV, especially those that cast it as a universal good (e.g., energy efficiency). PV is a peculiar consumer product. Its main purpose is to provide electricity, which most people already have. PV environmental benefits are invisible; some people value these benefits, whereas others do not even believe in them or are antagonized by the surrounding environmental claims or politics. Incentives aside, PV installation is often expensive. At least for purchased systems, favorable expected investment performance usually depends on having high baseline electricity use. Even then, there are considerable uncertainties over the long and largely irreversible product lifespan. While often sold as a financial investment, there are non-financial costs, risks, and benefits even beyond the environmental ones.

\subsection{Selling PV}

How PV is marketed and who it is marketed to shapes who buys it. It may often be in a "sold, not bought" category of goods. As Sigrin et al. (2015) note, even in California, some households must be recruited to adopt PV. The "sold, not bought" characterization contrasts with the storyline that PV adoption starts with active interest and a tight accompanying rationale in hand, such as saving money while protecting the environment. We saw that some households are deliberative about deciding on PV, carefully weighing costs and benefits. But, many seem more impressionistic or opportunistic, in particular when an installer sells to a homeowner who was not actively seeking PV. Similarly, satisfaction with the PV experience also keys to the level of detail (and accuracy) used in evaluating performance - did people get what they thought they 
would? Deliberation-based frameworks to understanding PV adoption may gloss over these consumer-level processes.

\subsection{Financial, Environmental, and Other Motives}

Over the past four decades, residential PV technologies have shifted from technological novelty, countercultural symbol, contributor to energy independence, and environmental symbol to what seems to be a chiefly financial proposition today. Saving money was the most prominent reason for PV adoption in our surveys. The array of incentives available, and the apparent importance of these in increasing PV sales, underscores the financial nature of PV adoption.

Money is a highly social concept and there is no singular way of figuring what is a good deal or not. The classic economic framing of energy efficiency as well as PV sees purchases as an investment with a payback period or rate of return on investment, so that a "good" decision depends on these estimates. Yet, nearly as many surveyed households named protection against future price increases as an important motivation for interest in, and adoption of, PV-despite the fact that retail electricity prices and tariffs are unpredictable over a 10-20 year horizon. PV adopters can know the future levelized cost of PV, so they can hedge against electricity price increases - which may provide a sense of comfort — but they cannot hedge against price decreases.

Deciding to install PV may also involve judgments about how PV could reduce stress and discomfort in the home, for example, by making bills more predictable, reducing the need to try to conserve energy, or reducing arguments families have about energy use. These are indirectly related to money but are not economic considerations traditionally applied to investments. In addition, some people might consider the pleasure derived from PV of using electricity from the sun or of being part of a solar community.

After money, the next most important motivation for most Adopters and many Considerers was the environmental properties of PV. For many households, these properties may be vague or symbolic rather than about a specific property, such as reducing greenhouse gas emissions due to the displacement of fossil fuels. The survey data indicated that few households prioritized environmental benefits over financial ones. Furthermore, the environmental associations of PV may play a more important role in initial PV interest rather than at later stages of consideration. And for some, the environmental association of PV was a negative. An increasing politicization of PV and environmental causes may heighten this tension.

\subsection{Deliberation and Information}

For anyone taking a classically economically rational approach to installing PV, a proper private cost-benefit analysis is complex and uncertain. This would involve assumptions about how much the system generates over time, future rates, net-metering, changes in demand, and so on. This kind of calculation is probably quite rare. In practice, different households will estimate expected savings differently and have different criteria for deciding whether PV is worth the costs and risks. One of the most common pathways may be relying on installers or trade industry calculator estimates to determine utility bill savings (Rai and Sigrin 2013). Where upfront costs are low (as in leasing situations) or heavily discounted (for those who get generous incentives), households may expend less effort in these calculations. Assessing the environmental benefits of a PV 
system is even harder. Such an assessment likely entails simply evaluating whether PV is "good for the environment" or helps with climate change, or deciding whether this question is immaterial or more about politics.

In our collected data, adopters and potential adopters of PV sometimes said that they wanted better information about PV but could not find it. There is a need for trustworthy information on PV, yet the tendency or perceived tendency of installers, trade organizations, and environmental organizations to present only largely positive information can present an incomplete picture. Keeping information about solar simple and positive likely makes adoption decisions easier for many households, but it may deter or mislead others.

In light of these complexities and uncertainties, households may often make decisions that are impressionistic and opportunistic rather than deliberative. Such impressionistic adoption may be becoming more common with the availability of TPO systems, because TPO requires less upfront commitment and generally has clearer costs and benefits than purchases. Decisions against $\mathrm{PV}$, or complete disinterest in considering it, may also often be impressionistic.

\subsection{After Adoption}

There is little research on how households that have installed PV view their systems and what may have changed about energy use after installation. The PV adopters we surveyed largely reported being happy with the results, sometimes even when savings were less than expected. However, 9\% said they had regrets about the systems they installed. Some were disappointed by their energy savings or frustrated by unexpected aspects of PV, problems with the installation, long wait times for incentives, big true-up bills, or the feeling they were being treated unfairly by the utility. Others had reservations about how leasing unfolded. Even without changing what is actually being offered, letting potential PV adopters know what to expect may reduce dissatisfactions,

\subsection{What about Non-Adopters?}

We argued that to understand future adoption, it is important to pay close attention to the diversity of non-adopters on their own terms, rather than just as "pre-adopters." The vast majority of U.S. households are non-adopters of PV. Some are demographically similar to adopters, but overall non-adopters have much lower average income and electricity costs than do adopters to date. To depict their diversity, we identified a number of non-adopter groups or tendencies. Some non-adopters were largely unaware of PV. Some were antagonistic. Some seemed to see little value in PV. Others judged PV as not economically, technically, or socially viable for their situation. However, nearly two thirds of the general population surveyed said they had thought about installing PV. This interest did not often translate to contacting an installer, even among those who said they would be happy to talk to one. Rather, most seem to be "waiting," whether for an installer to contact them, for improvements in technologies, price reductions, more attractive incentives, a better understanding of the entire process of installation, or more societal and peer experience. 


\section{Questions about PV's Future, Questions for Future Research}

Drawing from a particularly expansive set of survey data collected from U.S. households, we have tried to offer some new starting points for deliberations about PV adoption, and understanding the household circumstances within which PV operates, provides benefits, and entails costs. Our analyses were not focused on how to increase PV adoption, but the results can clarify that challenge and inform the development of marketing, development, and marketing strategies to better account for the diversity among consumer segments and speak to an evolution from "early adopters" to a broader market. Below, based on the survey data analysis, we offer suggestions about how research could help shape this future for the better.

\section{Questions about the future of PV}

- Value beyond the financial. What are the costs and benefits of promoting PV based primarily on its economic attributes? Are there other framings, technical attributes, or business models that could be enticing to a wider range of households? For example, what might encourage PV electricity to be perceived as worth more than normal gridsupplied electricity?

- Futures which may have vastly different consumer costs. What happens if and when PV incentives diminish or vanish? How will lower incentives sync with moderate-income and moderate-electricity-use households in terms of the economic proposition of PV? Conversely, what happens if PV costs decline further as the industry matures? Given the already high incomes and electricity use of most current PV adopters, why and how could PV appeal to lower-income and lower-energy-use households, where the value equation and methods of assessment might be different from those used by adopters in the past?

- Visions of future supply systems. Controversies now surrounding PV—related to rate structures and rules, long-term electricity-supply planning, environmental politics, equity, and other matters - could further complicate already-complex adoption decisions. How can these issues be managed to minimize the derailing of interest in PV?

\section{Research questions}

- Assessing the information landscape. Some households said they had enough information about PV to make their decision, others said that weighing the possibilities was complex and burdensome, and some said that the information they had was misleading or too selective. The complexity of the decision can inhibit households from installing, or even considering, PV. This has led to an information landscape that seems focused on simple, positive renditions of PV's costs, benefits, and risks. How can government, environmental organizations, research institutions, or other non-sales entities provide upto-date, balanced, and more trusted guidance? A detailed analysis of PV information search and decision processes among consumers could help.

- Using existing trust and connections. Most survey respondents said that, when it came to information on PV, they had far higher trust in friends, family, and other peers than in institutions. How can this peer experience be shared more broadly without being or appearing fake? In contrast to normal customer endorsements, which are normally highly 
positive, could wider availability of balanced reports - including lessons learned and things that went wrong - on the experience of PV purchase and use improve system adoption choices, expectations, and satisfaction?

- Monitoring post-PV experience to better understand the public benefits of PV. What happens after households adopt PV? How do PV adopters change how they think about energy, and how much energy they use? For example, if PV makes using additional central air conditioning very cheap, do households use more air conditioning, and with what (if any) consequences to the environmental benefits of PV?

- Monitoring post-PV experience to improve future offerings and experiences. Tracking households' longer-term experiences with PV could also help both marketing and system performance. These experiences, if systematically collected, could inform improvements to product offerings, technical characteristics and options, marketing, expectation setting, or benefits estimates. Given the common misperception that rooftop PV will protect homes from losing power during a blackout, could technological developments in inverters or battery backup increase interest in, and satisfaction with, PV? Could do-ityourself installation options (mentioned by some respondents; see also Dóci and Vasileiadou 2015) help bring in a different type of PV customer largely missing from current markets?

- What PV adoption niches do current systems and sales techniques miss? As is, different PV installation companies specialize in particular consumer interests, circumstances, and geographies, but some potential segments may be overlooked. For example, to what extent are people being alienated by current solar marketing or solar politics? Are women being relatively neglected in PV offerings? Could ground-mounted systems or positive renditions of community solar help deliver PV-based electricity to households that are otherwise not suited to it? 


\section{References}

Balcombe, P.; Rigby D.; and Azapagic A. (2013). "Motivations and Barriers associated with Adopting Microgeneration Energy Technologies in the UK." Renewable and Sustainable Energy Reviews 22: 655-666.

Balcombe, P.; Rigby D.; and Azapagic A. (2014). "Investigating the Importance of Motivations and Barriers Related to Microgeneration Uptake in the UK." Applied Energy 130: 403-418.

Barkenbus, J. (2013). “Indoor Thermal Comfort: The Behavioral Component.” Sustainability 5 (4):1680-1699.

Bass, F. M. (1969). “A New Product Growth for Model Consumer Durables.” Management Science 18: 215-227.

Bollinger, B.; and Gillingham, K. (2012). "Peer Effects in the Diffusion of Solar Photovoltaic Panels.” Marketing Science 31(6): 900-912.

Borenstein, S. (2012). "The Private and Public Economics of Renewable Electricity Generation." The Journal of Economic Perspectives 26(1): 67-92.

Borenstein, S. (2015). Private Net Benefits of Residential Solar PV: the Role of Electricity Tariffs, Tax Incentives, and Rebates. Energy Institute at Haas. Revised July 2015.

Broniarczyk, S.M.; and Griffin, J.G. (2014). "Decision Difficulty in the Age of Consumer Empowerment.” Journal of Consumer Psychology 24(4): 608-625.

Caird, S.; Roy, R.; and Herring, H. (2008). "Improving the Energy Performance of UK Households: Results from Surveys of Consumer Adoption and Use of Low-and Zero-Carbon Technologies." Energy Efficiency 1(2): 149-166.

Carlsson-Kanyama, A.; and Lindén, A.L. (2007). "Energy Efficiency in Residences-Challenges for Women and Men in the North." Energy Policy 35(4): 2163-2172.

Chen, K. (2013). “Assessing the Effects of Customer Innovativeness, Environmental Value and Ecological Lifestyles on Residential Solar Power Systems Installation Intention.” Energy Policy 67: 951-961.

Denholm, P.; Kuss, M.; and Margolis, R.M. (2013). "Co-benefits of Large Scale Plug-in Hybrid Electric Vehicle and Solar PV Deployment.” Journal of Power Sources 236: 350-356.

Dóci, G.; and Vasileiadou, E. (2015). “'Let's Do it Ourselves.' Individual Motivations for Investing in Renewables at Community Level." Renewable and Sustainable Energy 49: 41-50.

Dong, C.; and Sigrin, B. (2017). "Willingness-to-pay for solar photovoltaics: A parameterization and calibration approach" Working Paper. 
Drury, E.; Denholm, P.; and Margolis, R. (2011). Impact of Different Economic Performance Metrics on the Perceived Value of Solar Photovoltaics. Golden, CO: National Renewable Energy Laboratory. NREL/TP-6A20-52197.

Drury, E.; Miller, M.; Macal, C.; Graziano, D.; Heimiller, D.; Ozik, T.; and Perry, T. (2012). "The Transformation of Southern California's Residential Photovoltaics Market through ThirdParty Ownership". Energy Policy 42(March 2012): 681-690.

EERE (n.d.). The History of Solar. Energy Efficiency and Renewable Energy, U.S. Department of Energy.

EIA (U.S. Energy Information Administration). (2009). Residential Energy Consumption Survey Data, accessed December 1, 2016: http://www.eia.gov/consumption/residential/data/2009/ index.cfm?view=microdata.

EIA. (U.S. Energy Information Administration). (2013). Analysis and representation of miscellaneous electric loads in NEMS. December. U.S. Department of Energy. Washington, DC. https://www.eia.gov/analysis/studies/demand/miscelectric/pdf/miscelectric.pdf

EnergySage (2017). Solar Installer Survey: 2016 results. http://www.energysage.com/data/.

Faiers, A.; Neame, C. (2006). "Consumer attitudes towards domestic solar power systems.” Energy Policy 34(14): 1797-1806.

Freedman, D.A. (1991). "Statistical Models and Shoe Leather." Sociological Methodology; 21(2): 291-313.

Freedman, D.A. (2008). On types of scientific inquiry: The role of qualitative reasoning. The Oxford handbook of political methodology, pp. 300-318.

Gillingham, K.; Rapson, D.; and Wagner, G. (2016). "The rebound effect and energy efficiency policy." Review of Environmental Economics and Policy 10(1): 68-88.

Graziano, M.; and Gillingham, K. (2015). "Spatial Patterns of Solar Photovoltaic System Adoption: the Influence of Neighbors and the Built Environment." Journal of Economic Geography 15(4): 815-839.

Henry A.D.; and Brugger, H. (2015). "The equity of incentives: Agent-based explorations of how residential solar adoption incentives influence energy choices in segregated networks". Paper presented at 2015 APPAM Fall research conference. Miami, FL. November 2015

Hoen, B.; Wiser, R.; Thayer, M.; and Cappers, P. (2013). "Residential photovoltaic energy systems in California: the effect on home sales prices." Contemporary Economic Policy 31(4), 708-718.

Kahneman, D. (2003). "Maps of Bounded Rationality: Psychology for Behavioral Economics." The American Economic Review 93(5): 1449-1475. 
Keirstead, J. (2007). "Behavioural Responses to Photovoltaic Systems in the UK Domestic Sector." Energy Policy 35(8): 4128-4141.

Labay, D.G.; and Kinnear, T.C. (1981). "Exploring the consumer decision process in the adoption of solar energy systems.” Journal of Consumer Research 8(3): 271-278.

Lindstrom, M. (2016). Small Data: The Tiny Clues that Uncover Huge Trends. St. Martin's Press.

Maloney, P. (2016). "How well do Consumers Understand Rooftop Solar Economics?" UtilityDIVE. 14 July.

Merchant, C. (2014). Earthcare: Women and the Environment. Routledge.

Munien, S. (2014). "Rural energy profiles and the role of solar energy in climate change mitigation-a gendered perspective." Agenda 28(3): 115-126

Ornetzeder, M. (2001). "Old Technology and Social Innovations. Inside the Austrian Success Story on Solar Water Heaters." Technology Analysis \& Strategic Management 13(1): 105-115.

Owens, S.; and Driffill, L. (2008). "How to Change Attitudes and Behaviours in the Context of Energy.” Energy Policy 36(12): 4412-4418.

Palmer, J.; Sorda, G.; and Madlener, R. (2015). "Modeling the diffusion of residential photovoltaic systems in Italy: An agent-based simulation." Technological Forecasting and Social Change 99: 106-131.

Palm, J.; and Tengvard, M. (2011). "Motives for and Barriers to Household Adoption of SmallScale Production of Electricity: Examples from Sweden.” Sustainability: Science, Practice, \& Policy 7(1): 6-15.

Rai, V.; and McAndrews, K. (2012). "Decision-Making and Behavior Change in Residential Adopters of Solar PV." Proceedings of the World Renewable Energy Forum, Denver, CO, May 2012.

Rai, V.; and Sigrin, B. (2013). "Diffusion of Environmentally-Friendly Energy Technologies: Buy versus Lease Differences in Residential PV Markets.” Environ. Res. Lett. 8014022

Rai, V.; Reeves, D. C.; and Margolis, R. (2016). "Overcoming Barriers and Uncertainties in the Adoption of Residential Solar PV.” Renewable Energy 89 498-505.

Rai, V.; and Robinson, S.A. (2015). “Agent-Based Modeling of Energy Technology Adoption: Empirical Integration of Social, Behavioral, Economic, and Environmental factors." Environmental Modelling \& Software 70: 163-177.

Rogers, E.M. (2010). Diffusion of Innovations. Simon and Schuster. 
Schelly, C. (2014). "Residential Solar Electricity Adoption: What Motivates, and What Matters? A Case Study of Early Adopters.” Energy Research \& Social Science 2: 183-191.

Schelly, C. (2015). "What's Political about Solar Electric Technology? The User's Perspective." Engaging Science, Technology, and Society; 1(1): 25-46

Sigrin, B. (2013). Financial Modeling of Consumer Discount Rate in Residential Solar Photovoltaic Purchasing Decisions. Master's Thesis. University of Texas at Austin. May.

Sigrin, B.; Pless, J.; and Drury, E. (2015). "Diffusion into New Markets: Evolving Customer Segments in the Solar Photovoltaics Market." Environmental Research Letters, 10(8).

Smith, T.M.F. (1983). "On the Validity of Inferences from Non-Random Samples.” Journal of the Royal Statistical Society. Series A (General); 146(4): 394-403.

Simcock, N.; MacGregor S; Catney P.; Dobson A, Ormerod M.; Robinson Z.; Ross S.; Royston, S.; and Hall S.M. (2014). "Factors Influencing Perceptions of Domestic Energy Information: Content, Source and Process." Energy Policy 65(Feb): 455-464.

Simon, H. (1947). Administrative Behavior: A Study of Decision-Making Processes in Administrative Organization. New York: Macmillan.

Simpson, G.; and Clifton, J. (2015). "The Emperor and the Cowboys: The Role of Government Policy and Industry in the Adoption of Domestic Solar Microgeneration Systems." Energy Policy 81: 141-151.

Sommerfeld, J.; Buys, L. and Vine, D. (2017).” Residential consumers' experiences in the adoption and use of solar PV." Energy Policy 105:10-16.

Sommerfeld, J.; Buys, L. (2014). "Australian Consumer Attitudes and Decision Making on Renewable Energy Technology and its Impact on the Transformation of the Energy Sector." Open Journal of Energy Efficiency 3: 85-91.

Stern, P.C.; Janda, K.; Brown, M.; Steg, L.; Vine, E.; and Lutzenhiser, L. (2016). “Opportunities and Insights for Reducing Fossil Fuel consumption by Households and Organizations." Nature Energy 1.

Strauss, S..; Rupp, S.; and Love, T. eds. (2013). Cultures of Energy: Power, Practices, Technologies. Left Coast Press.

Stryi-Hipp, G. (2001). “European Solar Thermal Market.” Refocus, 2(5):32-36.

Theodori, G. L.; Luloff, A. E.; Willits, F. K.; and Burnett, D. B. (2014). Hydraulic fracturing and the management, disposal, and reuse of frac flowback waters: Views from the public in the Marcellus Shale. Energy Research \& Social Science, 2: 66-74.

Turaga, R. M. R.; Howarth, R. B.; and Borsuk, M. E. (2010). "Pro-Environmental Behavior." Annals of the New York Academy of Sciences, 1185(1): 211-224. 
U.S. Census Bureau. (2016). American Community Survey 5-year data. Generated by Mithra Moezzi using American FactFinder: http://factfinder.census.gov/faces/nav/jsf/pages/index.xhtml. Accessed November 1, 2016.

Vasseur, V.; Kemp, R. (2015). "The Adoption of PV in the Netherlands: A Statistical Analysis of Adoption Factors." Renewable and Sustainable Energy Reviews; 41: 483-494.

Wolske, K.; Paul Stern, and Tom Dietz. (2017). "Explaining Interest in Adopting Residential Solar Photovoltaic Systems in the United States: Towards an Integration of Behavioral Theories." Energy Research and Social Science.

Zhai, P.; Williams, E.D. (2012). Analyzing Consumer Acceptance of Photovoltaics (PV) using Fuzzy Logic Model." Renewable Energy 41: 350-357. 